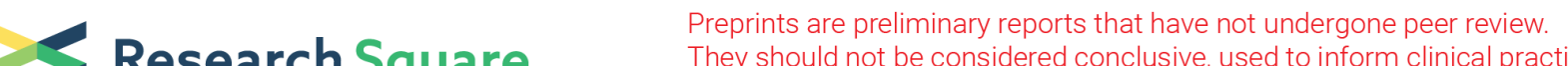 $\begin{array}{ll}\text { Research Square } & \text { They should not be considered conclusive, used to inform clinical practice, } \\ \text { or referenced by the media as validated information. }\end{array}$
}

\section{Pregnane X receptor exacerbates nonalcoholic fatty liver disease accompanied by obesity- and inflammation-prone gut microbiome signature}

\section{Sarah Kim}

University of Washington

\section{Sora Choi}

North Carolina Central University

Moumita Dutta

University of Washington

\section{Marianne Polunas}

Rutgers

\section{Michael Goedken}

Rutgers

\section{Frank Gonzalez}

Laboratory of Metabolism, Center for Cancer Research, National Cancer Institute, National Institutes of Health, Bethesda, Maryland https://orcid.org/0000-0002-7990-2140

Julia Yue Cui ( $\square$ juliacui@uw.edu )

University of Washington

\section{Maxwell Gyamfi}

North Carolina Central University

\section{Article}

Keywords: Gut Dysbiosis, Pro-inflammatory Cytokines, Firmicutes/Bacterioides Ration, Lactobacillus, Allabaculum, Bifidobacterum, Hepatic Steatosis

Posted Date: January 26th, 2021

DOl: https://doi.org/10.21203/rs.3.rs-134429/v1

License: (c) (1) This work is licensed under a Creative Commons Attribution 4.0 International License. Read Full License

Version of Record: A version of this preprint was published at Biochemical Pharmacology on November 1st, 2021. See the published version at https://doi.org/10.1016/j.bcp.2021.114698. 


\section{Abstract}

Pregnane $\mathrm{X}$ receptor (PXR) is a drug receptor with novel functions in promoting non-alcoholic fatty liver disease (NAFLD). We hypothesize that PXR worsens NAFLD accompanied by gut dysbiosis. Wild-type and PXR-knockout mice were fed control or high fat diet (HFD) for 16-weeks. Serum parameters, liver histopathology, transcriptomic profiling, 16S-rDNA sequencing, and bile acid (BA) metabolomics were performed. PXR enhanced HFD-induced weight gain, hepatic steatosis and inflammation especially in males, accompanied by male-specific and PXR-dependent up-regulation in pro-inflammatory cytokines and microbial response-related genes in liver, an increase in intestinal Firmicutes/Bacteroides ratio (hallmark of obesity) and the pro-inflammatory Lactobacillus, and a decrease in the anti-obese Allobaculum and the anti-inflammatory Bifidobacterum. The gut dysbiosis was associated with a reduction of hepatic beneficial BAs in males. In conclusion, PXR exacerbates hepatic steatosis and inflammation accompanied by obesity- and inflammation-prone gut microbiome signature, suggesting that gut microbiome may contribute to PXR-mediated exacerbation of NAFLD.

\section{Introduction}

NAFLD is a progressive disease associated with obesity, usually accompanied by steatosis and inflammation, potentially degenerating to non-alcoholic steatohepatitis (NASH) and liver cancer (1). NAFLD affects approximately $30-40 \%$ of the US and $25 \%$ of the world populations (1). Obesity and NAFLD have been linked with dysregulation of the gut microbiome $(2,3)$, including an increase in the Firmicutes/Bacteroidetes $(F / B)$ ratio, which is a well-established obesity biomarker $(4,5)$. The gut microbiome is also an important modifier of host xenobiotic biotransformation. Besides its wellcharacterized role in xenobiotic biotransformation, PXR plays novel roles in lipid and glucose metabolism (6). Human PXR gene variants are associated with disease severity in NAFLD (7), potentially leading to liver steatosis (8). PXR-KO mice are more resistant to diet-induced obesity, suggesting that PXR promotes metabolic syndrome $(9,10)$. However, the molecular mechanisms is unknown.

Aside from playing a role in energy metabolism (e.g. type 2 diabetes, obesity and hyperglycemia), pharmacological activation of PXR is known to have anti-inflammatory functions. The microbial tryptophan metabolite, Indole-3 propionic acid (IPA) is a novel PXR activator that down-regulates the proinflammatory tumor necrosis factor alpha (TNFa) and toll-like receptor (TLR) pathway in intestine of mice (11). The PXR ligand PCN is beneficial in reducing inflammation in a mouse model of inflammatory bowel disease (IBD) through inhibiting the nuclear factor kappa B (NF-KB) transcription factor and downregulating the NF-KB-targeted pro-inflammatory cytokines in mice (12). Activation of PXR also inhibits inflammation by inhibiting toll-like receptor (TLR4) pathway, thus preventing the overproduction of proinflammatory cytokines. This mechanism results to Listeria monocytogenes $(L M)$ infection in WT mice but not in PXR-KO mice $(13,14)$. Since inflammation is well-known to be an imbedded mechanism of many obesity-related diseases (15) and that PXR is known to have anti-inflammatory functions, it appears contradictory that PXR deficiency worsens obesity, highlighting the need for follow-up investigations regarding the interplay between PXR and inflammation during the pathogenesis of obesity. 
In addition to its well-characterized role in obesity, the gut microbiome is increasingly recognized as an important modifier for host xenobiotic biotransformation pathways and drug metabolism. In germ free (GF) mouse models, it was shown that the expression of xenobiotic-processing genes were altered, such as cytochrome P450 (Cyp) enzymes and other phase I oxidases (16). CYP3A, which is a prototypical target gene of PXR, metabolizes over $50 \%$ of prescription drugs that require biotransformation before clearance. In a previous study, it was shown that levels of Cyp3a11 and mRNA decreased by $87 \%$ in livers of GF mice, suggesting that the presence of gut microbiome is necessary in maintaining the constitutive PXR signaling in liver (17). The absence of gut microbiota mice also alters the host metabolism of the environmental pollutant polybrominated diphenyl ethers (PBDEs), and modulates the PBDE-mediated differential regulation of xenobiotic-processing genes (18). In summary, the gut microbiome is an important modulator for host xenobiotic metabolism and PXR signaling.

Another important class of intermediary metabolites that contribute to obesity is bile acids (BAs). BAs are important metabolic sensors that aid in dietary nutrient absorption to provide fuel for energy metabolism and biosynthesis (19). Cholic acid (CA), a primary liver-derived BA, decreases high-density lipoprotein (HDL) cholesterol, plasma apolipoprotein Al and hepatic apolipoprotein AI mRNA in mice (20). Additionally, CA supplementation in HFD-fed mice improved glucose tolerance and decreased total body fat accretion and fasting blood glucose concentrations $(21,22)$. Another study showed that high levels of BAs induced by HFD could impair intestinal stem cell function by triggering endoplasmic reticulum (ER) stress, resulting in the disruption of the intestinal mucosal barrier in mice (23). Secondary BAs such as deoxycholic acid (DCA) and lithocholic acid (LCA), which are produced by the gut microbiome, are important activators of the host TGR- 5 receptor, which promotes thermogenesis and energy expenditure (24). Therefore, these microbial derived BAs are thought to be anti-obesity hormones. LCA at high concentrations also activate the PXR-target gene Cyp3a11 to protect liver injury in mice, highlighting the importance of gut microbiome in modulating the hepatic PXR-signaling (25). When BAs are toxic at high concentrations such as during cholestasis, PXR acts in concert with the major BA receptor farnesoid $X$ receptor (FXR) to modulate BA detoxification and elimination (26). BAs also serve as an important host factor shaping the gut microbiome in diet-induced obese mice, and this effect was more pronounced in PXR-KO mice, suggesting that PXR contributes to the weakening of the effect of BAs on lipoprotein metabolism (27). BA represents a highly abundant pool of host-derived and microbial modified metabolites that are major regulators of the gut microbiome, which can be a key finding for more effective probiotic treatments for patients suffering from obesity and metabolic syndrome. Recent studies have shown that xenobiotic exposure and exposure to nuclear receptors are an important factor in both dietary and chemical models of nonalcoholic fatty liver disease (NAFLD) in mice $(28,29)$. Another study also stated that PXR gene variants are associated with disease severity in NAFLD with the xenobiotic exposure (7) that may also lead to steatosis in the liver of mice and human (8). Therefore, it is reasonable to speculate that the therapeutic modulation of PXR and BAs may be beneficial in managing diabetes and metabolic diseases.

We and other research groups have recently demonstrated that PXR can modulate the gut microbiome. The pharmacological activation of PXR by its prototypical ligands PCN alters the composition of the gut 
microbiome by down-regulating certain BA-metabolizing bacteria in the intestine (30). Mice treated with the PXR activator statins gained weight, had increased members of the S24-7 family (a commensal bacteria in the intestine), up-regulated PXR-target genes in mice, as well as increased DCA. All of these metabolic endpoints were found to be PXR-dependent (31). Mice orally-gavaged with the non-coplanar PBDEs, which are PXR activators (32), had increased numbers of Akkermansia muciniphila and Allobaculum spp., as well as unconjugated secondary BAs (33). Additionally, mice dosed with polychlorinated biphenyls (PCBs), which also activate PXR (34), had increased numbers of Akkermansia muciniphila, Clostridium scindens, Enterococcus sp., and Prevotella sp. and serum BAs (35).

Furthermore, absence of PXR results in higher microbial richness and enriched pro-inflammatory bacteria, suggesting that the basal function of PXR is to maintain immune surveillance to prevent pathogen infections (Little et al. 2020 https://doi.org/10.21203/rs.3.rs-36593/v1). In summary, the gut microbiome composition and functions can be modulated by PXR under pharmacological, toxicological, and physiological conditions.

While there are many studies demonstrating the effects of PXR and the gut microbiome on obesity, the extent of the interaction between PXR and the gut microbiome in the pathogenesis of obesity has not been characterized. Furthermore, the role of PXR in sex differences in obesity remains to be investigated. Therefore, this study aims to delineate the potential relationship and we hypothesize that the presence of PXR promotes obesity by modifying the gut-liver axis in a sex-specific manner.

\section{Results}

\section{EFFECT OF HIGH FAT DIET ON OBESITY PHENOTYPES}

Adult male and female WT and PXR-KO mice were fed either a standard rodent chow diet or a HFD diet for 16 weeks. The depletion of PXR in PXR-KO was confirmed by RT-qPCR in livers of these mice (Fig. S1). Daily food consumption by weight was higher in HFD-fed mice group than control diet-fed group of the same genotypes and sexes (Fig. S2). In addition, HFD-fed female PXR-KO mice consumed less food than female WT mice (Fig. S2).

In both male and female WT mice, HFD markedly increased the body weight starting from Week 2 to the end of the HFD exposure at week 16 (Fig. 1A). Interestingly, although HFD also increased the body weight of both male and female PXR-KO mice, the onset of weight gain occurred much later than in HFD-fed WT mice, which was Week 9 in male PXR-KO and week 7 in female PXR-KO mice. In addition, the percentage of weight gain in both male and female PXR-KO mice was markedly attenuated at all time points, as compared to the HFD-fed WT mice of the same sex.

In male mice, HFD increased both the absolute liver weight and liver to-body-weight ratio in a PXRdependent manner (Table 1). In female mice, HFD did not alter the absolute liver weight or liver to-bodyweight ratio in WT mice, whereas it decreased the liver/body weight ratio in PXR-KO mice. In male mice, HFD did not alter the mass of the epididymal white adipose tissue (WAT) in either genotype; however, in females, HFD increased the WAT mass in both genotypes, and the presence of PXR resulted in a greater 
WAT mass gain. HFD increased mesenteric WAT mass in all groups except for female PXR-KO mice where no change was observed (Table 1). HFD increased brown adipose tissue (BAT) mass in a PXRdependent manner. HFD did not alter the lean mass in any groups; however, HFD increased the fat mass of both males and females in a PXR-dependent manner. Together, these observations suggest that the presence of PXR promotes obesity related metabolic parameters and male mice are more susceptible to HFD-induced liver and fat mass gain than females.

Regarding the serum metabolic parameters, as shown in Table 1, in males, HFD increased serum alanine aminotransferase (ALT), which is a well-established biomarker for liver injury (36), increased serum total bile acids (BAs), which is an indicator of cholestatic liver injury (37) and increased fibroblast growth factor 21 (FGF21), which is a liver-derived hormone that promotes hepatic fatty acid oxidation, ketogenesis, and insulin sensitivity (38), all in a PXR-dependent manner. Interestingly, in HFD-fed female mice, serum ALT, BAs, or Fgf21 were unchanged in either genotype. In male mice, HFD increased serum insulin in both WT and PXR-KO mice; whereas in females, HFD did not have any effect in either WT or PXR-KO conditions. HFD increased fasting glucose in male PXR-KO mice, but did not have any effect in other groups. Serum leptin was increased by HFD in both sexes and genotypes, whereas serum adiponectin was not altered in any group. These observations suggest that both the presence of PXR and the male sex render the mice more susceptible to HFD-induced injuries than females. However, whereas HFD-induced liver injury and lipid disorders were promoted by PXR, PXR may be beneficial in maintaining insulin sensitivity (as evidenced by increased fasting glucose in male PXR-KO mice).

H\&E staining was performed in control and HFD-fed mice to determine the effects of PXR and sex on lipid accumulation and inflammation. The presence of PXR promoted HFD-induced substantial increase in lipid accumulation (observed mostly as macrovesicular with some microvesicular steatosis) as well as greater inflammatory cell infiltration in both male and female WT mice, whereas such phenotype was much attenuated in the absence of PXR in both sexes (Fig.1B-1D). In addition, HFD-fed male WT mice had even more lipid accumulation and inflammation than HFD-fed female WT mice. Col1a1 mRNA was increased by HFD in male mice in a PXR-dependent manner; COL1A1 is a well-known early biomarker for liver fibrosis and hepatocellular carcinoma (39). Mild necrosis was also observed in livers of HFD-fed male WT mice with no noteworthy signs of apoptosis, fibrosis, and/or biliary hyperplasia by HFD exposure in either sexes or genotypes (Data not shown). HFD increased the levels of hepatic triglyceride in PXR-dependent manner in both sexes (Fig. S3A). In summary, these results indicate that PXR in both male and female mice promotes HFD-induced body weight gain, steatosis, inflammation and hepatic triglyceride accumulation.

\section{EFFECT OF HIGH FAT DIET ON GLUCOSE TOLERANCE}

Impaired glucose tolerance is the earliest identifiable metabolic abnormality in the pathogenesis of type II diabetes. To establish whether PXR or sex has any influence on insulin signaling and glucose clearance, a glucose tolerance test was performed in control- or HFD-fed male and female WT and PXR-KO mice (Fig. 
1E). Notably, in male mice, deficiency of PXR resulted in a higher area under the curve (AUC) of serum glucose in both control diet and HFD groups. This observation aligns with the finding that PXR-KO males had elevated increased fasting glucose (Table 1), and suggests that PXR is beneficial in maintaining insulin signaling in males. However, in female mice, PXR worsens the ability to clear glucose, because HFD-fed female WT mice had higher AUC than in HFD-fed female PXR-KO mice (Fig. S3B). Together these observations suggest that although the presence of PXR worsens HFD-induced lipid accumulation and inflammation, its role in insulin signaling is divergent and sex-specific.

\section{HFD-MEDIATED FUNCTIONAL CHANGES PREDICTED FROM HEPATIC TRANSCRIPTOMIC RESPONSE}

To examine the role of PXR in the HFD-mediated hepatic transcriptomic response in liver, we employed microarray and predicted functional changes using Gene ontology (GO) enrichment analysis. HFD produced a distinct separation in the liver transcriptomes in both genotypes and sexes (Fig. S4). Interestingly, the presence of PXR was associated with the HFD-mediated hepatic up-regulation in multiple pro-inflammatory signaling pathways and microbial responses in male mice (Fig. 2A), suggesting the presence of a leaky gut. These observations suggest the importance of an indirect role for PXR in regulating the gut microbiome community to modify hepatic transcriptome along the gut-liver axis. In contrast, in livers of male PXR-KO mice, neither pro-inflammation nor microbial response pathways were enriched (FDR $<0.01$ cut-off, Fig. 2B).

In male mice, the presence of PXR did not enrich down-regulated hepatic pathways following HFDexposure (Fig. 2C); whereas the absence of PXR potentiated HFD-mediated down-regulation of several pathways related to immune cell mobilization/infiltration (Fig. 2D) and positive regulation of leukocyte and cell activation. Other down-regulated functions related to immune response include antimicrobial humoral immune response mediated by antimicrobial peptide and acute inflammatory response. In addition, the down-regulation of superoxide anion generation and sensory responses was potentiated by the absence of PXR.

In HFD-fed female mice, the absence of PXR potentiated the up-regulation of pathways involved in proinflammation and microbial response (Fig. S5A-S5B), suggesting that PXR in females may render protection against HFD-induced injuries (Fig. S5). The presence of PXR drives the HFD-mediated downregulation of several lipid and nucleotide metabolism pathways, whereas the absence of PXR potentiates the hepatic down-regulation of pathways involved in hormonal response and thermogenesis in females (Fig. S5C-S5D).

Together these observations suggested PXR-dependent and sex-divergent regulation of the hepatic transcriptome following HFD exposure. Observations in HFD-fed male mice suggest that PXR contributes to HFD-induced liver injury in male mice by promoting pro-inflammatory cascade and microbial response and preventing the down-regulation of immune cell infiltration and oxidative stress. Observations in HFD- 
fed female mice suggest that PXR offers protection against HFD-induced liver injury by preventing a proinflammatory cascade and microbial response.

\section{HFD-INDUCED PXR-DEPENDENT AND -INDEPENDENT GENE EXPRESSION IN LIVER}

To determine the importance of PXR in HFD-mediated changes in intermediary metabolism, microarray analysis was done for differentially regulated genes involved in the following pathways: lipid metabolism, carbohydrate metabolism, cholesterol and BA metabolism, as well as nuclear receptor signaling (Fig. 3A). In WT male livers, HFD increased the expression of lipid metabolism-related genes Abcd2, Apoa4, and Echs1, but decreased the expression of cholesterol metabolism-related genes Abca1, Cyp4a12a, and Cyp4a12b and the BA synthetic enzyme Cyp7a1, all in a PXR-dependent manner (Fig. 3A). In WT female livers, HFD increased the expression of lipid metabolism-related genes Acadm, Apoc2, Elov/3, and Mtor and most of the genes related to cholesterol and BA metabolism (S/c10a2, Abcb4, and Srebf2 except for Mbtps1), whereas HFD decreased the expression of lipid metabolism-related genes Fabp5 and Slc25a17, most of the genes related to glucose and glycogen metabolism (Gpd2, Gpi1, and Pyglexcept for Entpd5), and nuclear receptor genes $\mathrm{Nr} 2 \mathrm{c1}$ and $\mathrm{Nr3c1}$ in a PXR-dependent manner (Fig. 3B).

In male PXR-KO mice livers, HFD increased the expression of some genes related to lipid metabolism (Acaa1a, Apoa1, Hadha, and Phyh) and glucose metabolism (Gpd1 and Pdha1), but decreased the expression of other genes related to lipid metabolism ( Npc2 and Ppargc1a) and cholesterol metabolism (Sqle) (Fig. 3C). In female PXR-KO mice livers, HFD increased the expression of lipid metabolism-related genes Decr2 and Fads1 and the glucose metabolism-related gene Gck (Fig. 3D).

To examine the potential therapeutic significance of hepatic transcriptomic changes following HFD treatment, we compared PXR-dependent gene expression signatures with the Library of Integrated Network-Based Cellular Signatures (LINCS) L1000 database (Fig. 3E). In Fig. 3E (top left), the drugs and endogenous ligands that most closely match the up-regulated signatures for male PXR-dependent changes by HFD are all cancer-related (details described in Table S2-3). In females, PXR dependent HFDmediated gene expression signatures match the LINCS L1000 database related to innate immunity, selfregulation, and cancer treatment (Table S4-5). In summary, the gene expression signature resembled the ones in LINCS database of inflammation, self-regulation, and cancer treatments. These therapeutic options may be beneficial to mitigate PXR-dependent liver toxicities.

\section{EFFECT OF HFD ON GUT MICROBIOTA DIVERSITY}

.Alpha diversity, which is a measure of the richness of the gut microbiome, was determined using the Chao 1 index (QIIME). Only males showed significant differences in species richness of the gut microbiome (alpha diversity) (Fig. S7A). Regarding beta diversity, there was a distinct separation between control and HFD-fed groups in WT males; however, there was minimal separation between 
control and HFD-fed groups for WT females, also for both sexes of PXR-KO mice (Fig. S7C-F). The top 14 most abundant taxa are shown in Fig. S8A-B. Most of these taxa were altered by diet and genotype, which mostly belong to the Firmicutes phylum.

Notably, in males, PXR was associated with a more stringent separation in the gut microbiome composition between control and HFD treated groups (Fig. 4A), whereas a more diffusive and overlapping pattern was observed between control and HFD fed male PXR-KO mice and female mice of both genotypes. Interestingly, there was a PXR-dependent and male-specific down-regulation of the antiinflammatory Bifidobacterium genus and in the pro-inflammatory Lactobacillus genus (Fig. 4B), indicating a pro-inflammatory microbial signature that is associated with increased liver inflammation and liver injuries. The anti-obesity marker Allobaculum (35) was down-regulated by HFD in a malespecific PXR-dependent manner, whereas the two pro-inflammatory taxa Ruminococcus gnavus and Peptococcaceae were down-regulated in a PXR-dependent manner in females.

\section{UNIQUE MICROBIAL BIOMARKERS AND EFFECT OF HFD ON FIRMICUTES/BACTEROIDETES (F/B) RATIO}

The most prominent microbial biomarkers in each treatment group varied by sex, genotype and diet as follow in Fig. 5A. The $F / B$ ratio, an indicator of obesity (36), was up-regulated by HFD in male (and to a much lesser extent female) WT mice in a PXR-dependent manner (Fig. 5B). Moreover, the $F / B$ ratio remained unchanged by HFD in female PXR-KO mice. Thus, it is possible that PXR exacerbates dietinduced obesity partly through modulation of the gut microbiome.

\section{CORRELATIONS AMONG DIFFERENTIALLY REGULATED INTESTINAL BACTERIA, BONA FIDE PXR- TARGET GENES, AND LIVER BAs FOLLOWING HFD TREATMENT}

Pearson's correlation was performed between differentially regulated intestinal bacteria and PXR-target genes that are differentially regulated by HFD in a PXR-dependent manner (i.e. bona fide PXR-target genes), as well as between differentially regulated bacteria and hepatic BAs (Fig. 6A-D). For bona fide PXR-target genes, we focused on 3 categories, xenobiotic biotransformation (including BA-metabolizing enzymes), energy metabolism, and inflammation.

In general, there were more intestinal bacteria and PXR-target genes associations in male mice than female mice. In male mice, 3 taxa in the Bifidobacterium genus were negatively associated with drugprocessing genes and inflammation genes, whereas, 3 taxa in the Lactobacillus genus were positively associated with drug-processing and inflammation genes (Fig. 6A-B).

In male livers, there was a positive association between Allobaculum, S24-7, and Bifidobacterium genus in intestine and most of the liver BAs, except for T-aMCA and T-BMCA, which were negatively associated (Fig. 6C). Conversely, there was a negative association between Lactobacillus genus and Bacteroides 
caccae and most of the liver BAs except for LCA which was positively associated (Fig. 6C). In female livers, there was a positive association between Desulfovibrio with most of the liver BAs except for TaMCA, T- BMCA, T-LCA, DCA, and LCA, which had negative association (Fig. 6D). However, there was a negative association between Allobaculum with most of the liver BAs except for T-LCA, which had positive association and T-HDCA. Furthermore, for Faecalibacterium prausnitzii, Jeotgalicoccus, Paenibacillus, Parabacteroides distasonis, and Collinsella aerofaciens, negative associations were shown in most of the liver BAs except for T-LCA, which was positively associated (Fig. 6D).

\section{Discussion}

Our study demonstrated that PXR is necessary in modulating the gut microbiome-liver axis to impact the susceptibility to HFD-induced obesity in a sex-specific manner, and gut microbiome is likely a mechanistic component in augmenting the liver steatosis and inflammation in PXR-carriers. As illustrated in Fig. 7, in males, PXR is necessary for HFD-induced body weight gain and serum injury markers, worsened hepatic steatosis and inflammation, up-regulation of pro-inflammatory cytokines, prevention of decrease in chemokines, and up-regulation of microbial response genes in liver (indicating a leaky gut). Besides the phenotypic parameters, the PXR is necessary for the distinct separation of microbiome signatures driven by HFD, increased $F / B$ ratio (hallmark for obesity), decreased anti-obesity taxon Allobaculum, decreased anti-inflammatory taxa Bifidobacterium, and increased Lactobacillus taxa, which are anti-inflammatory for probiotic use $(40,41)$, but it is actually shown to be pro-inflammatory endogenously $(42,43)$. PXRdependent depletion of beneficial BAs by intestinal bacteria following HFD treatment may serve as an additional mechanism for worsened liver injuries. The protective mechanisms of PXR in females may be through PXR-mediated prevention in up-regulating of pro-inflammatory cytokines and microbial response genes, PXR-mediated decrease in steatosis-related gene expression, constitutive expression of thermogenesis and energy expenditure related genes in female livers. The female-specific resistance to HFD induced liver injury may also be contributed by PXR-mediated down-regulation of pro-inflammatory bacteria (Ruminococcus gnavus and Peptococcaceae).

It is well known that inflammation is a critical mechanistic contributor to the toxicity of calories following HFD-induced obesity $(15,44-46)$. Prolonged HFD feeding in mice has been shown to lead to hepatic and colon inflammation as well as changes in the gut microbiome towards a pro-inflammatory configuration (47), however, very little is known regarding how PXR contributes to this process. Interestingly, pharmacological activation of PXR is well known to be anti-inflammatory through NFKB-signaling attenuation, which in turn reduces the expression of pro-inflammatory cytokines in animal models that recapitulate inflammatory bowel disease (14). Pharmacological activation of PXR has also been shown to be anti-inflammatory and anti-fibrogenic in cultured hepatocytes and mouse liver (48). In contrast to these previous findings, our study demonstrated for the first time that during HFD-induced obesity, the presence of PXR actually promotes hepatic inflammation, collagen 1a mRNA increase, as well as upregulation of both innate and adaptive immune response in liver in male mice. 
PXR is also necessary in preventing the HFD-mediated down-regulation of hepatic pro-inflammatory signaling in male mice. Therefore, there appears to be context-specific duality of PXR in modulating inflammation during pharmacological (anti-inflammatory) and pathophysiological (pro-inflammatory) conditions. Also in contrast to a previous study which demonstrated that the presence of PXR is necessary in preventing a leaky intestinal epithelium pathology under basal conditions (11), we observed that the presence of PXR is necessary in HFD-mediated hepatic increase in multiple pathways involved in defense against microbial response, suggesting that PXR contributes to bacterial translocation to liver during HFD-induced obesity to further exacerbate hepatic inflammation. Last but not least, pharmacological activation of PXR using the prototypical PXR ligand PCN reduced in abundance of Bifidobacterium spp., which has shown to protect the intestinal epithelial barrier in inflammatory models (30), however, in our study, we demonstrated that the presence of PXR is necessary in HFD-mediated decrease in Bifidobacterium spp.. Again, these observations have highlighted the context-specific duality of PXR under basal, pharmacological, and pathophysiological conditions.

Importantly, the present study is also among the first to show that during HFD-feeding, the presence of PXR is necessary in priming the gut microbiome towards an obesity-prone microbial configuration, and suggests that the gut microbiome serves as a mechanistic contributor to the exacerbation to HFDinduced obesity and liver injuries in PXR-carriers. Interestingly, the anti-obesity biomarker Allobaculum (49) was down-regulated by HFD in a PXR-dependent manner in both sexes, which supports that PXR aggravates HFD-induced obesity. In a previous study, Lactobacillus has been shown to be higher in obese people (50), suggesting that PXR contributes to weight gain through Lactobacillus. As for $F / B$ ratio, previous studies have shown that $F / B$ ratio was increased during obesity $(4,5)$. In our study, $F / B$ ratio was up-regulated by HFD in male WT mice in a PXR-dependent manner, suggesting that PXR prevented the HFD-induced increase in the $F / B$ ratio and underlining the essential role of PXR in exacerbating diet-induced obesity through gut microbiome modulations. The observation that $F / B$ ratio was not altered by HFD in female mice suggests that this may be the reason for female-specific resistance to HFD-induced obesity and remained unchanged by HFD in female PXR-KO mice. Together these observations support that PXR is necessary in modulation of the gut microbiome in a sex-specific manner, and this may contribute to the pathogenesis of diet-induced obesity.

Distinct BAs are known to contribute to diet-induced obesity. In previous studies, supplementation of HFD with CA or CDCA and UDCA suppressed the developmental of obesity in mice $(24,51)$. Pearson correlation was used to identify relationships between the differentially regulated PXR-dependent by HFD taxa and liver BAs. In male mice, Lactobacillus was negatively associated with most of the BAs, whereas Allobaculum and Bifidobacterium genus were positively associated with most of the BAs. However, in female mice, Allobaculum genus was negatively associated with most of the BAs. In our study, Allobaculum and Bifidobacterium genus were down-regulated by HFD in male WT mice and had strong positive correlations with TCA, TCDCA, CA, CDCA, and UDCA, suggesting that these BAs could contribute to alleviation of diet-induced obesity. Another study suggested that FGF21 signaling is required for the beneficial effect of CA through decreasing the hepatic triacylglycerol (21). In this study, in male WT mice, FGF21 was increased but was not able to protect against hepatic steatosis, suggesting that the 
compensatory up-regulation of FGF21 is necessary but not sufficient in alleviating the obesity phenotypes.

In a previous study, the constitutive androstane receptor (CAR) was shown to profoundly influence the composition of the gut microbiome, which may contribute to the basal gut cytokine levels that predispose certain individuals to GI inflammation (Little et al. 2020 https://doi.org/10.21203/rs.3.rs-36593/v1). In another study, CAR showed anti-diabetic and anti-obesity effects from HFD-induced obesity mice model with a CAR agonist 1,4-bis[2-(3,5 dichloropyridyloxy)] benzene (TCPOBOP) (52). In addition, the Cyp2b gene family are well known prototypical CAR-target genes, and can be profoundly induced by TCPOBOP (52). Interestingly, in our study, Сyp2b9 and Cyp2b13 mRNAs were up-regulated by HFD in a PXRdependent manner in livers of male mice. This suggests that there is a crosstalk between PXR and CAR during HFD-induced obesity. PXR and CAR are known to share many common target genes (53), however, it is important to note their metabolic roles during HFD feeding are different, in that PXR worsens HFDinduced obesity through modulating the gut microbiome and hepatic inflammation (present study), whereas CAR alleviates HFD-induced obesity through modulating lipid and carbohydrate pathways in liver and adipose tissue (52).

The present study predicted the end-stage disease outcomes through comparing the HFD-regulated, PXRdependent hepatic transcriptomic signatures with the Diseases/Drugs panel from the LINCS 1000 database. The hepatic transcriptome signatures resemble pro-carcinogenic profile, because the majority of the top hits are anti-cancer drugs, which indicate that chronic HFD-induced hepatic steatosis and inflammation may eventually lead to liver cancer through PXR.

Overall, this study suggests the mechanisms underlying the PXR-dependent exacerbation of HFD-induced obesity may involve the contribution from the gut microbiome, which enhances the hepatic microbial response and the subsequent increase in hepatic inflammation. Therefore, targeting the gut microbiome may serve as a novel approach to modulating the hepatic PXR-signaling and obesity outcomes.

\section{Declarations}

Conflict of Interest: The authors have no conflicts of interest.

\section{Authors contribution statement:}

Concept and Design: Sarah Kim, Julia Yue Cui, Maxwell A. Gyamfi

Experiments and procedures: Sarah Kim, Julia Yue Cui, Moumita Dutta, Sora Choi, Maxwell A. Gyamfi, Frank J. Gonzalez, Michael Goedken, Marianne Polunas

Writing of article: Sarah Kim, Julia Yue Cui, Maxwell A. Gyamfi 


\section{Acknowledgements}

The authors would like to thank the UW DEOHS IT team for technical assistance and the members of Drs. Gyamfi and Cui laboratories for helping tissue collection and manuscript revision.

\section{Supplementary Data}

Supplementary data are available at Hepatology journal website and liver microarray and 16S rDNA sequencing data at Dyrad.

\section{Financial Support:}

Supported by the National Institutes of Health (NIH) grants 1U54MD012392, and U54 AA019765 and R01 AA028806 (Gyamfi), NIH grants R01 ES030197, P30 ES007033, and the University of Washington Sheldon Murphy Endowment (Cui), as well as the graduate student fellowship from the UW Provost funds (Kim). Also supported in part by the National Cancer Institute Intramural Research Program, $\mathrm{NIH}$ (Gonzalez).

\section{Materials And Methods}

ANIMALS. Male and female C57BL/ 6 mice (WT) and PXR-KO mice in C57BL/ 6 background (10-12 weeks of age) were fed either control diet (12\% fat calories) or HFD ( $45 \%$ fat calories) from Research Diets Inc. (New Brunswick, NJ) for 16 weeks as previously described (8) ( $n=7-12 /$ group). Animals were housed at $22^{\circ} \mathrm{C}$ with a 12/12-h light/dark cycle at the Animal Resources Complex at North Carolina Central University (NCCU), randomly assigned to two groups ( $n=7-12 /$ group), and fed either control diet (12\% fat calories) or HFD (45\% fat calories) from Research Diets Inc. (New Brunswick, NJ) for 16 weeks as previously described (8). Food consumption and body weight were monitored weekly. All procedures were approved by the NCCU Institutional Animal Care and Use Committee (IACUC). After 16 weeks, various tissues were collected, weighed, snap-frozen in liquid nitrogen and stored at $-80{ }^{\circ} \mathrm{C}$. Livers were divided into two portions; one homogenized and the other fixed in $10 \%$ formalin for hematoxylin and eosin ( $\mathrm{H} \& \mathrm{E})$ staining. Blood samples collected by cardiac puncture were processed for serum and stored at $-80^{\circ} \mathrm{C}$ prior to analyses of liver enzymes, BAs, fibroblast growth factor 21 (FGF21), leptin, adiponectin, and insulin. 
BODY COMPOSITION. At 12-weeks of diet treatment, body composition (fat mass, lean mass, free water, and total water) was determined in vivo ( $\mathrm{n}=4$ /group) using the quantitative magnetic resonance (QMR) (EchoMRI $^{\text {TM }}$ 3-in-1; Echo MRI LLC, Houston, TX).

BACTERIAL 16S rRNA SEQUENCING. Bacterial DNA and amplicon sequencing was isolated from large intestinal content (LIC) pellet using an OMEGA E.Z.N.A. Stool DNA Kit (OMEGA Biotech, Inc, Norcross, Georgia). Qubit fluorometer (Thermo Fisher Scientific, Waltham, Massachusetts) was used to determine concentration of DNA. Bacterial DNA was sequenced using an Illumina HiSeq 2500 second-generation sequencing system (250 bp paired-end; $n=5-6 /$ group; Novogenes, Sacramento, $C A$ ) for bacterial $16 \mathrm{~S}$ rDNA V4 amplicon sequencing. FASTQ files were analyzed using various python scripts in QIIME. Statistical differences were determined by using three-way ANOVA followed by Tukey's post hoc test and adjusted $p$-value $<0.05$ in $R$.

METABOLIC PARAMETERS. Serum ALT activity was determined using a commercially available kit (Sigma-Aldrich, St. Louis, MO). Serum BAs, leptin, and insulin levels were determined by ELISA according to manufacturer instructions (Crystal Chem Inc., Dowers Grove, IL), as were serum adiponectin and FGF21 levels (Millipore Corporation, Billerica, MA). For hepatic triglyceride levels, total liver lipids were extracted from $100 \mathrm{mg}$ of liver homogenate using methanol and chloroform as previously described (22). Hepatic triglycerides were quantified using a triglyceride test kit (Wako Pure Chemical Industries, Richmond, VA).

H\&E STAINING OF LIVER SECTIONS. Livers were fixed in 10\% neutral-buffered formalin, sectioned and stained with H\&E prior to blinded evaluation by a board-certified veterinary pathologist. Liver sections were semi-quantitatively scored for lipid accumulation, necrosis, inflammation, fibrosis (increased fibrocytes and collagen fibers), and biliary hyperplasia (increased numbers of oval and/or intercalated cells in cholangioles). The basic scoring criteria was as follows: no significant lesions (0); minimal lesions, less than 10\% accumulation/injury/death (1); mild lesions, 10-25\% (2); moderate lesions, 25-40\% (3); marked lesions, $40-50 \%$ (4); severe lesions, changes in 50\% or greater (5). Lipid accumulation was characterized and scored on the amount of clear, round, single membrane bound cytoplasmic lipid vacuoles. Histomorphological signs of necrosis were pyknosis, karyolysis, karyorrhexis, cytoplasmic hypereosinophilia, membrane disruption and cell loss while signs of inflammation were edema and leukocyte accumulation. Fibrosis was recognized by replacement of damaged tissue by angiogenic connective tissue. Apoptotic characteristics were chromatin condensation, cell shrinkage and formation of cytoplasmic blebs. 
GLUCOSE TOLERANCE TEST (GTT). At 15-weeks of diet treatment, intraperitoneal glucose tolerance test (IGTT) was performed in overnight fasted animals ( $n=7-9 /$ group) over a time course. A single dose of $D-$ glucose ( $10 \%$ solution in water, $10 \mathrm{~mL} / \mathrm{kg}$ ) was injected intraperitoneally (i.p.). Tail vein glucose was quantified immediately before and 15, 30, 60, 90, and 120 min after glucose injection using Contour TS strips (Bayer HealthCare LLC, Mishawaka, IN).

PREPARATION OF SOLUTIONS FOR BA STANDARD CURVE INTERNAL STANDARDS (ISs). Cholic acid (CA), chenodeoxy cholic acid (CDCA), deoxycholic acid (DCA), lithocholic acid (LCA), a muricholic acid (aMCA), BMCA, WMCA, ursodeoxycholic acid (UDCA), hyodeoxycholic acid (HDCA), murideoxycholic acid (MDCA), taurine conjugated cholic acid (T-CA), T-CDCA, T-DCA, T-LCA, T- aMCA, T- $\beta M C A, T-\omega M C A, T-$ UDCA, and T-HDCA were purchased from Steraloids (Newport, Rhode Island). T- $\omega$ MCA was given by Dr. Daniel Raftery's laboratory at the University of Washington Northwest Metabolomics Research Center (Li et al. 2018; Roeske and Chollet 1987). For ISs, a total of 5 deuterated (d4) ISs were used. Among them the d4-cholic acid (d4-CA) was purchased from Toronto Research Chemicals Inc (Ontario, Canada), the d4deoxycholic acid (d4-DCA) and d4-chenodeoxycholic acid (d4-CDCA) were purchased from CDN Isotope Inc (Pointe-Claire, Quebec, Canada), the d4-glycine conjugated CDCA (d4-G-CDCA) was purchased from IsoSciences (Ambler, PA), and d4-lithocholic acid (d4-LCA) was purchased from Steraloids (Newport, Rhode Island). One $\mathrm{mg} / \mathrm{mL}$ stock solutions of the individual BAs (for standard curve) and IS were prepared in methanol and water (1:1). The 19 individual BA stock solutions were further diluted in 50\% methanol to obtain 10 working standard solutions ranging from $0.05-10000 \mathrm{ng} / \mathrm{mL}$ ). The $5 \mathrm{ISs}$ were mixed to obtain a working IS solution in which the concentration of each IS was $10 \mu \mathrm{mol} / \mathrm{mL}$.

\section{QUANTIFICATION OF MRNA LEVELS USING REAL-TIME POLYMERASE CHAIN REACTION (REAL-TIME} PCR). Total RNA $(5 \mu \mathrm{g})$ was reversed transcribed into CDNA with random hexamer primers using Tetro cDNA Synthesis Kit (Bioline, Taunton, MA) and real-time quantitative PCR to quantify the mRNA levels were performed as we previously described $(6,54)$. The following mRNAs were quantified: Estrogen receptor a (Era), constitutive androstane receptor (Car), Pxr, Cyp3a11, Organic Anion Transporter 2 (Oatp2), Cyp2C29, Cyp2c55, Cyp2b9, Cyp2b10, Cyp2b13, Ucp2, PPARy coactivator 1a (Pgc-1a), collagen $1 a$, Transforming growth factor $\beta$ (Tgf $\beta$ ), Uridine diphosphate glucuronosyltransferase 1A1 (Ugt1a1), and Gapdh. The primer sequence for Pxr, Car, Cyp3a11, Cyp2b10, Ucp2, Oatp2, and Gapdh were previously published (54). Furthermore, the following proprietary Taqman Gene Expression Assays were purchased from Applied Biosystems/Life Technologies (Grand Island, NY) and used for real-time quantitative PCR: Era (No. Mm00433149_m1), Cyp2b9 (No. Mm00657910_m1), Cyp2b13(No. Mm03052613_s1), Cyp2c29 (No. Mm00725580_s1), and Cyp2c55(No. Mm00472168_m1). The amplification reactions were performed in the $\mathrm{ABI}$ QuantStudio ${ }^{\mathrm{TM}} 3$ Systems (Applied Biosystems, Foster City, CA). Results were presented as levels of expression relative to that of controls after normalizing with Gapdh mRNA using the comparative CT method. 
BA EXTRACTION AND UPLC-MS/MS QUANTIFICATION. BAs from liver, small intestinal content (SIC), and LIC pellets were extracted and analyzed by UPLC-MS using a Waters Acquity I-Class UPLC TQS-micro MS system (Waters, Milford, Massachusetts). BAs were extracted from liver, SIC, and LIC pallets by adding 5 $\mu \mathrm{l}$ of ice-cold analytical grade $\mathrm{H}_{2} \mathrm{O}$ per $\mathrm{mg}$ of sample then homogenized in a glass Dounce homogenizer until uniform. $250 \mu \mathrm{l}$ of homogenate was removed and mixed with $10 \mu \mathrm{l}$ of the following internal standards (ISs). Samples were then precipitated in acetonitrile with $5 \% \mathrm{NH}_{4} \mathrm{OH}$ and centrifuged to obtain pellets. After, pellets were resuspended with $750 \mu \mathrm{l}$ of $100 \%$ methanol, centrifuged, and the supernatant was removed and dried under vacuum $\left(30^{\circ} \mathrm{C}\right)$ for about 4 hours. For serum, $50 \mu$ of serum was mixed with $10 \mu \mathrm{l}$ of IS, precipitated with ice-cold methanol, centrifuged, and the supernatant was dried under vacuum. The precipitates were then reconstituted in $100 \mu \mathrm{l}$ of $50 \%$ methanol water solution prior to LCMS. Preparation of BA standard curve and internal standards (IS) is described in Supplemental methods. Then, $5 \mu$ of bile acid extractions were injected into UPLC-MS/MS for analysis. Quality control (QC) samples and standard stock solutions for calibration were similarly extracted and analyzed.

MICROARRAY ANALYSIS. Transcriptomic profiling in livers was performed using Affymetrix GeneChip ${ }^{\circledR}$ arrays ( $n=4 /$ treatment/genotype/sex). Selected gene expression was determined using RT-qPCR. CEL files were analyzed in $\mathrm{R}$ using the oligo package. Genes with an average probe intensity $>100$ were considered to be significantly expressed. Probe IDs were annotated using the clariomsmousehttranscriptcluster.db package. Upper quartile normalization and differential expression between vehicle and HFD-exposed groups of the same genotype and sex was determined using EdgeR. The RUVSeq package was used to remove unwanted variations as described previously, and genes with a false discovery rate below 0.05 were considered statistically significant. Volcano plots and heatmaps were plotted for the differentially regulated genes with at least $50 \%$ up- or down-regulation using prcomp and ComplexHeatmap, respectively. Pathway analysis was performed using the R package TopGo. Bar plots of representative differentially regulated genes were generated using SigmaPlot (Systat Software, Inc). Total RNA were isolated with Trizol from liver tissues of male and female WT and PXR-KO mice fed control or a HFD for 16 weeks and purified using RNeasy spin columns (Germantown, MD), according to the supplier's instructions. The quality of the RNA was evaluated by measuring the 260:280 nm absorbance ratios, and the integrity of $18 \mathrm{~S}$ and $28 \mathrm{~S}$ ribosomal RNA bands assessed by electrophoresis. Total RNA (250 ng) was used to synthesize fragmented and labeled sense-strand CDNA and hybridize onto Affymetrix arrays. The Affymetrix GeneChip ${ }^{\circledR}$ WT PLUS Reagent Kit Manual were followed to prepare the samples. Briefly, the GeneChip ${ }^{\circledR}$ WT PLUS Reagent Kit (Affymetrix) was used to generate sense-strand cDNA from total RNA. Following synthesis of sense-strand cDNA, the cDNA was fragmented and labeled with the Affymetrix GeneChip Terminal Labeling Kit. Fragmented and labeled cDNA were then added to a hybridization cocktail $(25 \mu \mathrm{g} / \mu \mathrm{l}$ fragmented cDNA, $50 \mathrm{pM}$ control oligonucleotide B2, BioB, BioC, BioD and cre hybridization controls, $7 \%$ DMSO, $100 \mathrm{mM}$ MES, $1 \mathrm{M}[\mathrm{Na}+], 20 \mathrm{mM}$ EDTA, 0.01\% Tween 20). Affymetrix arrays (Affymetrix, Santa Clara, CA) were hybridized for 16 hours at $45^{\circ} \mathrm{C}$ in the 
GeneChip Hybridization Oven 645 (Affymetrix). The arrays were washed and stained with R-phycoerythrin streptavidin in the GeneChip Fluidics Station 450 (Affymetrix). The arrays were scanned with the GeneChip Scanner 3000 7G Plus with autoloader. GeneChip Command Console Software (AGCC) was used for washing, staining and scanning control of the instrumentation.

Principle component analysis. Principle component analysis (PCA) was performed of gut microbiome at L7 species level with mean \%OTU $>0.001 \%$ using the prcomp function in R and visualized using the ggbiplot R package.

Pearson's correlation analysis. Person's correlation analysis was performed using the ggplot2 and reshape2 $\mathrm{R}$ packages.

\section{References}

1. Younossi ZM, Koenig AB, Abdelatif D, Fazel Y, Henry L, Wymer M. Global epidemiology of nonalcoholic fatty liver disease-Meta-analytic assessment of prevalence, incidence, and outcomes. Hepatology. 2016;64(1):73-84.

2. Drissi F, Merhej V, Angelakis E, El Kaoutari A, Carrière F, Henrissat $B$, et al. Comparative genomics analysis of Lactobacillus species associated with weight gain or weight protection. Nutr Diabetes. 2014;4(2):e109.

3. Clarke SF, Murphy EF, Nilaweera K, Ross PR, Shanahan F, O'Toole PW, et al. The gut microbiota and its relationship to diet and obesity: new insights. Gut Microbes. 2012;3(3):186-202.

4. Turnbaugh PJ, Ley RE, Mahowald MA, Magrini V, Mardis ER, Gordon JI. An obesity-associated gut microbiome with increased capacity for energy harvest. Nature. 2006;444(7122):1027-31.

5. Sivamaruthi BS, Kesika P, Suganthy N, Chaiyasut C. A Review on Role of Microbiome in Obesity and Antiobesity Properties of Probiotic Supplements. Biomed Res Int. 2019;2019:3291367.

6. Spruiell K, Richardson RM, Cullen JM, Awumey EM, Gonzalez FJ, Gyamfi MA. Role of pregnane X receptor in obesity and glucose homeostasis in male mice. J Biol Chem. 2014;289(6):3244-61.

7. Sookoian S, Castaño GO, Burgueño AL, Gianotti TF, Rosselli MS, Pirola CJ. The nuclear receptor PXR gene variants are associated with liver injury in nonalcoholic fatty liver disease. Pharmacogenet Genomics. 2010;20(1):1-8.

8. Merrell MD, Cherrington NJ. Drug metabolism alterations in nonalcoholic fatty liver disease. Drug Metab Rev. 2011;43(3):317-34.

9. He J, Gao J, Xu M, Ren S, Stefanovic-Racic M, O'Doherty RM, et al. PXR ablation alleviates dietinduced and genetic obesity and insulin resistance in mice. Diabetes. 2013;62(6):1876-87. 
10. Ma Y, Liu D. Activation of pregnane $X$ receptor by pregnenolone 16 a-carbonitrile prevents high-fat diet-induced obesity in AKR/J mice. PLoS One. 2012;7(6):e38734.

11. Venkatesh M, Mukherjee S, Wang H, Li H, Sun K, Benechet AP, et al. Symbiotic bacterial metabolites regulate gastrointestinal barrier function via the xenobiotic sensor PXR and Toll-like receptor 4. Immunity. 2014;41(2):296-310.

12. Shah YM, Ma X, Morimura K, Kim I, Gonzalez FJ. Pregnane X receptor activation ameliorates DSSinduced inflammatory bowel disease via inhibition of NF-kappaB target gene expression. Am J Physiol Gastrointest Liver Physiol. 2007;292(4):G1114-22.

13. Qiu Z, Cervantes JL, Cicek BB, Mukherjee S, Venkatesh M, Maher LA, et al. Pregnane X Receptor Regulates Pathogen-Induced Inflammation and Host Defense against an Intracellular Bacterial Infection through Toll-like Receptor 4. Sci Rep. 2016;6:31936.

14. Cheng J, Shah YM, Gonzalez FJ. Pregnane X receptor as a target for treatment of inflammatory bowel disorders. Trends Pharmacol Sci. 2012;33(6):323-30.

15. Ellulu MS, Patimah I, Khaza'ai $H$, Rahmat $A$, Abed Y. Obesity and inflammation: the linking mechanism and the complications. Arch Med Sci. 2017;13(4):851-63.

16. Fu ZD, Selwyn FP, Cui JY, Klaassen CD. RNA-Seq Profiling of Intestinal Expression of Xenobiotic Processing Genes in Germ-Free Mice. Drug Metab Dispos. 2017;45(12):1225-38.

17. Klaassen CD, Cui JY. Review: Mechanisms of How the Intestinal Microbiota Alters the Effects of Drugs and Bile Acids. Drug Metab Dispos. 2015;43(10):1505-21.

18. Li CY, Lee S, Cade S, Kuo LJ, Schultz IR, Bhatt DK, et al. Novel Interactions between Gut Microbiome and Host Drug-Processing Genes Modify the Hepatic Metabolism of the Environmental Chemicals Polybrominated Diphenyl Ethers. Drug Metab Dispos. 2017;45(11):1197-214.

19. Ferrell JM, Chiang JYL. Understanding Bile Acid Signaling in Diabetes: From Pathophysiology to Therapeutic Targets. Diabetes Metab J. 2019;43(3):257-72.

20. Masson D, Lagrost L, Athias A, Gambert P, Brimer-Cline C, Lan L, et al. Expression of the pregnane X receptor in mice antagonizes the cholic acid-mediated changes in plasma lipoprotein profile. Arterioscler Thromb Vasc Biol. 2005;25(10):2164-9.

21. Ippagunta SM, Kharitonenkov A, Adams AC, Hillgartner FB. Cholic Acid Supplementation of a HighFat Obesogenic Diet Suppresses Hepatic Triacylglycerol Accumulation in Mice via a Fibroblast Growth Factor 21-Dependent Mechanism. J Nutr. 2018;148(4):510-7.

22. Ferrell JM, Boehme S, Li F, Chiang JY. Cholesterol 7a-hydroxylase-deficient mice are protected from high-fat/high-cholesterol diet-induced metabolic disorders. J Lipid Res. 2016;57(7):1144-54.

23. Huang $D$, Xiong $M, X u X, W u X, X u J$, Cai $X$, et al. Bile acids elevated by high-fat feeding induce endoplasmic reticulum stress in intestinal stem cells and contribute to mucosal barrier damage. Biochem Biophys Res Commun. 2020;529(2):289-95.

24. Watanabe M, Houten SM, Mataki C, Christoffolete MA, Kim BW, Sato H, et al. Bile acids induce energy expenditure by promoting intracellular thyroid hormone activation. Nature. 2006;439(7075):484-9. 
25. Staudinger JL, Goodwin B, Jones SA, Hawkins-Brown D, MacKenzie KI, LaTour A, et al. The nuclear receptor PXR is a lithocholic acid sensor that protects against liver toxicity. Proc Natl Acad Sci U S A. 2001;98(6):3369-74.

26. Han B, Kim B-K, Kim K, Fang S. Essential roles of bile acids and their nuclear receptors, FXR and PXR, in the cholestatic liver disease. Animal Cells and Systems. 2016;20(4):175-8.

27. Zheng X, Huang F, Zhao A, Lei S, Zhang Y, Xie G, et al. Bile acid is a significant host factor shaping the gut microbiome of diet-induced obese mice. BMC Biol. 2017;15(1):120.

28. Klaunig JE, Li X, Wang Z. Role of xenobiotics in the induction and progression of fatty liver disease. Toxicol Res (Camb). 2018;7(4):664-80.

29. Li X, Wang Z, Klaunig JE. Modulation of xenobiotic nuclear receptors in high-fat diet induced nonalcoholic fatty liver disease. Toxicology. 2018;410:199-213.

30. Dempsey JL, Wang D, Siginir G, Fei Q, Raftery D, Gu H, et al. Pharmacological Activation of PXR and CAR Downregulates Distinct Bile Acid-Metabolizing Intestinal Bacteria and Alters Bile Acid Homeostasis. Toxicol Sci. 2019;168(1):40-60.

31. Caparrós-Martín JA, Lareu RR, Ramsay JP, Peplies J, Reen FJ, Headlam HA, et al. Statin therapy causes gut dysbiosis in mice through a PXR-dependent mechanism. Microbiome. 2017;5(1):95.

32. Pacyniak EK, Cheng X, Cunningham ML, Crofton K, Klaassen CD, Guo GL. The flame retardants, polybrominated diphenyl ethers, are pregnane $X$ receptor activators. Toxicol Sci. 2007;97(1):94-102.

33. Li CY, Dempsey JL, Wang D, Lee S, Weigel KM, Fei Q, et al. PBDEs Altered Gut Microbiome and Bile Acid Homeostasis in Male C57BL/6 Mice. Drug Metab Dispos. 2018;46(8):1226-40.

34. Wahlang B, Prough RA, Falkner KC, Hardesty JE, Song M, Clair HB, et al. Polychlorinated BiphenylXenobiotic Nuclear Receptor Interactions Regulate Energy Metabolism, Behavior, and Inflammation in Non-alcoholic-Steatohepatitis. Toxicol Sci. 2016;149(2):396-410.

35. Cheng SL, Li X, Lehmler HJ, Phillips B, Shen D, Cui JY. Gut Microbiota Modulates Interactions Between Polychlorinated Biphenyls and Bile Acid Homeostasis. Toxicol Sci. 2018;166(2):269-87.

36. Lala V, Goyal A, Bansal P, Minter DA. Liver Function Tests. StatPearls. Treasure Island (FL): StatPearls Publishing Copyright ( 2 2020, StatPearls Publishing LLC.; 2020.

37. Luo L, Aubrecht J, Li D, Warner RL, Johnson KJ, Kenny J, et al. Assessment of serum bile acid profiles as biomarkers of liver injury and liver disease in humans. PLoS One. 2018;13(3):e0193824.

38. Potthoff MJ, Inagaki T, Satapati S, Ding X, He T, Goetz R, et al. FGF21 induces PGC-1alpha and regulates carbohydrate and fatty acid metabolism during the adaptive starvation response. Proc Natl Acad Sci U S A. 2009;106(26):10853-8.

39. Ma HP, Chang HL, Bamodu OA, Yadav VK, Huang TY, Wu ATH, et al. Collagen $1 A 1$ (COL1A1) Is a Reliable Biomarker and Putative Therapeutic Target for Hepatocellular Carcinogenesis and Metastasis. Cancers (Basel). 2019;11(6).

40. Kim DH, Kim S, Lee JH, Kim JH, Che X, Ma HW, et al. Lactobacillus acidophilus suppresses intestinal inflammation by inhibiting endoplasmic reticulum stress. J Gastroenterol Hepatol. 2019;34(1):178- 
85.

41. Oliveira M, Bosco N, Perruisseau G, Nicolas J, Segura-Roggero I, Duboux S, et al. Lactobacillus paracasei reduces intestinal inflammation in adoptive transfer mouse model of experimental colitis. Clin Dev Immunol. 2011;2011:807483.

42. Rocha-Ramírez LM, Pérez-Solano RA, Castañón-Alonso SL, Moreno Guerrero SS, Ramírez Pacheco A, García Garibay M, et al. Probiotic Lactobacillus Strains Stimulate the Inflammatory Response and Activate Human Macrophages. J Immunol Res. 2017;2017:4607491.

43. Chetwin E, Manhanzva MT, Abrahams AG, Froissart R, Gamieldien H, Jaspan H, et al. Antimicrobial and inflammatory properties of South African clinical Lactobacillus isolates and vaginal probiotics. Sci Rep. 2019;9(1):1917.

44. Duan Y, Zeng L, Zheng C, Song B, Li F, Kong X, et al. Inflammatory Links Between High Fat Diets and Diseases. Front Immunol. 2018;9:2649.

45. Rodríguez-Hernández H, Simental-Mendía LE, Rodríguez-Ramírez G, Reyes-Romero MA. Obesity and inflammation: epidemiology, risk factors, and markers of inflammation. Int J Endocrinol. 2013;2013:678159.

46. Wu H, Ballantyne CM. Metabolic Inflammation and Insulin Resistance in Obesity. Circ Res. 2020;126(11):1549-64.

47. Velázquez KT, Enos RT, Bader JE, Sougiannis AT, Carson MS, Chatzistamou I, et al. Prolonged highfat-diet feeding promotes non-alcoholic fatty liver disease and alters gut microbiota in mice. World $\mathrm{J}$ Hepatol. 2019;11(8):619-37.

48. Sun M, Cui W, Woody SK, Staudinger JL. Pregnane X receptor modulates the inflammatory response in primary cultures of hepatocytes. Drug Metab Dispos. 2015;43(3):335-43.

49. Ravussin Y, Koren O, Spor A, LeDuc C, Gutman R, Stombaugh J, et al. Responses of gut microbiota to diet composition and weight loss in lean and obese mice. Obesity (Silver Spring). 2012;20(4):738-47.

50. Million M, Maraninchi M, Henry M, Armougom F, Richet H, Carrieri P, et al. Obesity-associated gut microbiota is enriched in Lactobacillus reuteri and depleted in Bifidobacterium animalis and Methanobrevibacter smithii. Int J Obes (Lond). 2012;36(6):817-25.

51. Zhang Y, Zheng X, Huang F, Zhao A, Ge K, Zhao Q, et al. Ursodeoxycholic Acid Alters Bile Acid and Fatty Acid Profiles in a Mouse Model of Diet-Induced Obesity. Front Pharmacol. 2019;10:842.

52. Gao J, He J, Zhai Y, Wada T, Xie W. The constitutive androstane receptor is an anti-obesity nuclear receptor that improves insulin sensitivity. J Biol Chem. 2009;284(38):25984-92.

53. Cui JY, Klaassen CD. RNA-Seq reveals common and unique PXR- and CAR-target gene signatures in the mouse liver transcriptome. Biochim Biophys Acta. 2016;1859(9):1198-217.

54. Choi S, Neequaye P, French SW, Gonzalez FJ, Gyamfi MA. Pregnane X receptor promotes ethanolinduced hepatosteatosis in mice. The Journal of biological chemistry. 2018;293(1):1-17.

\section{Table}


Table 1. Body weight and food intake of adult (8-10 weeks) male and female wild type (WT, C57BL/6J) and PXR-KO mice and after 16 weeks on a control or a high-fat diet (HFD). 


\begin{tabular}{|c|c|c|c|c|c|c|c|c|}
\hline \multirow[b]{2}{*}{ Weights } & \multicolumn{2}{|l|}{ Male WT } & \multicolumn{2}{|c|}{ Female WT } & \multicolumn{2}{|c|}{ Male PXR-KO } & \multicolumn{2}{|c|}{ Female PXR-KO } \\
\hline & $\begin{array}{l}\text { Control } \\
(n=7)\end{array}$ & $\begin{array}{l}\text { HFD } \\
(n=9)\end{array}$ & $\begin{array}{l}\text { Control } \\
(n=7)\end{array}$ & $\begin{array}{l}\text { HFD } \\
(n=8)\end{array}$ & $\begin{array}{l}\text { Control } \\
(n=11)\end{array}$ & $\begin{array}{l}\text { HFD } \\
(n=12)\end{array}$ & $\begin{array}{l}\text { Control } \\
(n=11)\end{array}$ & $\begin{array}{l}\text { HFD } \\
(n=11)\end{array}$ \\
\hline Initial weight (g) & $\begin{array}{l}24.6 \pm \\
2.1\end{array}$ & $\begin{array}{l}24.8 \pm \\
2.4\end{array}$ & $\begin{array}{l}20.0 \pm \\
1.4^{\ddagger}\end{array}$ & $\begin{array}{l}20.4 \pm \\
1.4\end{array}$ & $\begin{array}{l}23.9 \pm \\
1.8\end{array}$ & $\begin{array}{l}23.6 \pm \\
1.6\end{array}$ & $\begin{array}{l}19.9 \pm \\
1.9^{\ddagger}\end{array}$ & $\begin{array}{l}20.0 \pm \\
1.5\end{array}$ \\
\hline Final weight (g) & $\begin{array}{l}35.9 \pm \\
3.6\end{array}$ & $\begin{array}{l}50.5 \pm \\
1.8^{\#}\end{array}$ & $\begin{array}{l}27.0 \pm \\
3.3\end{array}$ & $\begin{array}{l}44.3 \pm \\
4.7^{\#}\end{array}$ & $\begin{array}{l}31.4 \pm \\
3.0\end{array}$ & $\begin{array}{l}39.1 \pm \\
5.1^{\#, \dagger}\end{array}$ & $\begin{array}{l}25.3 \pm \\
1.7\end{array}$ & $\begin{array}{l}32.4 \pm \\
6.3^{\# \S}\end{array}$ \\
\hline $\begin{array}{l}\text { Absolute } \\
\text { liver weight (g) }\end{array}$ & $\begin{array}{l}1.5 \pm \\
0.1\end{array}$ & $\begin{array}{l}2.7 \pm \\
0.2^{\#}\end{array}$ & $\begin{array}{l}1.2 \pm \\
0.1\end{array}$ & $\begin{array}{l}1.5^{ \pm} \\
0.1^{\beta}\end{array}$ & $\begin{array}{l}1.6 \pm \\
0.1\end{array}$ & $\begin{array}{l}1.9 \pm \\
0.2^{\dagger}\end{array}$ & $\begin{array}{l}1.4 \pm \\
0.1\end{array}$ & $\begin{array}{l}1.3^{ \pm} \\
0.1^{\beta}\end{array}$ \\
\hline $\begin{array}{l}\text { Liver/body } \\
\text { weight (\%) }\end{array}$ & $\begin{array}{l}4.1 \pm \\
0.1\end{array}$ & $\begin{array}{l}5.4 \pm \\
0.4^{\#}\end{array}$ & $\begin{array}{l}4.4 \pm \\
0.2\end{array}$ & $\begin{array}{l}3.3^{ \pm} \\
0.2^{\boldsymbol{\beta}}\end{array}$ & $\begin{array}{l}5.0 \pm \\
0.1\end{array}$ & $\begin{array}{l}4.9 \pm \\
0.3\end{array}$ & $\begin{array}{l}5.6 \pm \\
0.2\end{array}$ & $\begin{array}{l}4.1 \pm \\
0.1^{\#}\end{array}$ \\
\hline $\begin{array}{l}\text { Epididymal WAT } \\
\text { mass }(\mathrm{g})\end{array}$ & $\begin{array}{l}2.0 \pm \\
0.2\end{array}$ & $\begin{array}{l}1.7 \pm \\
0.1\end{array}$ & $\begin{array}{l}0.9 \pm \\
0.2\end{array}$ & $\begin{array}{l}3.3 \pm \\
0.2^{\#, \beta}\end{array}$ & $\begin{array}{l}1.1 \pm \\
0.1\end{array}$ & $\begin{array}{l}1.8 \pm \\
0.1\end{array}$ & $\begin{array}{l}0.8 \pm \\
0.1\end{array}$ & $\begin{array}{l}2.2 \pm \\
0.3^{\#, \S}\end{array}$ \\
\hline $\begin{array}{l}\text { Mesenteric WAT } \\
\text { mass (g) }\end{array}$ & $\begin{array}{l}0.5 \pm \\
0.04\end{array}$ & $\begin{array}{l}1.1 \pm \\
0.1^{\#}\end{array}$ & $\begin{array}{l}0.4 \pm \\
0.1\end{array}$ & $\begin{array}{l}1.3 \pm \\
0.2^{\#}\end{array}$ & $\begin{array}{l}0.4 \pm \\
0.1\end{array}$ & $\begin{array}{l}0.9 \pm \\
0.1^{\#}\end{array}$ & $\begin{array}{l}0.3 \pm \\
0.03\end{array}$ & $\begin{array}{l}0.6 \pm \\
0.10^{\S}\end{array}$ \\
\hline BAT (g) & $\begin{array}{l}0.4 \pm \\
0.02\end{array}$ & $\begin{array}{l}0.6 \pm \\
0.04^{\#}\end{array}$ & $\begin{array}{l}0.2 \pm \\
0.01\end{array}$ & $\begin{array}{l}0.5 \pm \\
0.1^{\#}\end{array}$ & $\begin{array}{l}0.3 \pm \\
0.03\end{array}$ & $\begin{array}{l}0.4 \pm \\
0.04^{\dagger}\end{array}$ & $\begin{array}{l}0.3 \pm \\
0.02\end{array}$ & $\begin{array}{l}0.3 \pm \\
0.04, \S\end{array}$ \\
\hline $\begin{array}{l}{ }^{1} \text { Lean Mass at } 3 \\
\text { months }(\mathrm{g})\end{array}$ & $\begin{array}{l}25 \pm \\
0.3\end{array}$ & $\begin{array}{l}27 \pm \\
1.3\end{array}$ & $\begin{array}{l}19 \pm \\
0.7^{\ddagger}\end{array}$ & $\begin{array}{l}21 \pm \\
0.7^{\beta}\end{array}$ & $\begin{array}{l}24 \pm \\
0.3\end{array}$ & $\begin{array}{l}23 \pm \\
0.3^{\dagger}\end{array}$ & $\begin{array}{l}21 \pm \\
0.4\end{array}$ & $\begin{array}{l}21 \pm \\
0.5\end{array}$ \\
\hline $\begin{array}{l}{ }^{1} \text { Fat Mass at } 3 \\
\text { months }(\mathrm{g})\end{array}$ & $4 \pm 0.6$ & $\begin{array}{l}13 \pm \\
1.9^{\#}\end{array}$ & $3 \pm 0.1$ & $\begin{array}{l}9 \pm \\
0.8^{\#, \beta}\end{array}$ & $4 \pm 0.4$ & $\begin{array}{l}8 \pm \\
0.3^{\dagger}\end{array}$ & $\begin{array}{l}3.3 \pm \\
0.7\end{array}$ & $7 \pm 0.7$ \\
\hline Serum & Control & HFD & Control & HFD & Control & HFD & Control & Control \\
\hline Parameters & $(n=5-7)$ & $\begin{array}{l}(n=5- \\
9)\end{array}$ & $(n=5-7)$ & $\begin{array}{l}(n=5- \\
8)\end{array}$ & $(n=5-8)$ & $\begin{array}{l}(n=5- \\
8)\end{array}$ & $(n=5-9)$ & $(n=5-9)$ \\
\hline ALT (IU/L) & $\begin{array}{l}27.1 \pm \\
4.8\end{array}$ & $\begin{array}{l}82.6 \pm \\
9.0^{\#}\end{array}$ & $\begin{array}{l}21.7 \pm \\
4.1\end{array}$ & $\begin{array}{l}35.1^{ \pm} \\
11.5^{\beta}\end{array}$ & $\begin{array}{l}27.7 \pm \\
2.6\end{array}$ & $\begin{array}{l}22.6 \pm \\
4.7^{\dagger}\end{array}$ & $\begin{array}{l}24.7 \pm \\
5.8\end{array}$ & $\begin{array}{l}36.4 \pm \\
17.5\end{array}$ \\
\hline $\begin{array}{l}\text { Bile Acids } \\
(\mu \text { mole/L) }\end{array}$ & $\begin{array}{l}37.3 \pm \\
2.4\end{array}$ & $\begin{array}{l}62.1 \pm \\
4.2^{\#}\end{array}$ & $\begin{array}{l}32.2 \pm \\
2.0\end{array}$ & $\begin{array}{l}33.5 \pm \\
3.7\end{array}$ & $\begin{array}{l}35.6 \pm \\
1.7\end{array}$ & $\begin{array}{l}42.1 \pm \\
7.0^{+}\end{array}$ & $\begin{array}{l}34.8 \pm \\
3.7\end{array}$ & $\begin{array}{l}35.6 \pm \\
4.0\end{array}$ \\
\hline FGF21 (pg/mL) & $\begin{array}{l}764 \pm \\
84\end{array}$ & $\begin{array}{l}1343 \pm \\
187^{\#}\end{array}$ & $\begin{array}{l}275 \pm \\
85\end{array}$ & $\begin{array}{l}614^{ \pm} \\
125^{\beta}\end{array}$ & $\begin{array}{l}225 \pm \\
74\end{array}$ & $\begin{array}{l}356 \pm \\
69^{+}\end{array}$ & $\begin{array}{l}337 \pm \\
92\end{array}$ & $\begin{array}{l}453 \pm \\
86\end{array}$ \\
\hline $\begin{array}{l}\text { Adiponectin } \\
(\mathrm{ng} / \mathrm{mL})\end{array}$ & $\begin{array}{l}11.1 \pm \\
0.7\end{array}$ & $\begin{array}{l}9.4 \pm \\
0.4\end{array}$ & $\begin{array}{l}17.0 \pm \\
0.4^{\ddagger}\end{array}$ & $\begin{array}{l}18.3^{ \pm} \\
0.7^{\beta}\end{array}$ & $\begin{array}{l}7.7 \pm \\
0.7\end{array}$ & $\begin{array}{l}7.4 \pm \\
0.6\end{array}$ & $\begin{array}{l}16.2 \pm \\
1.8^{\ddagger}\end{array}$ & $\begin{array}{l}16.0 \pm \\
0.8^{\boldsymbol{\beta}}\end{array}$ \\
\hline Insulin (pg/mL) & $\begin{array}{l}2.4 \pm \\
0.7\end{array}$ & $\begin{array}{l}19.5 \pm \\
2.1^{\#}\end{array}$ & $\begin{array}{l}1.7 \pm \\
0.6\end{array}$ & $\begin{array}{l}2.3^{ \pm} \\
0.8^{\beta}\end{array}$ & $\begin{array}{l}0.9 \pm \\
0.4\end{array}$ & $\begin{array}{l}14.4 \pm \\
5.5^{\#}\end{array}$ & $\begin{array}{l}0.7 \pm \\
0.1\end{array}$ & $\begin{array}{l}1.1^{ \pm} \\
0.2^{\beta}\end{array}$ \\
\hline
\end{tabular}




\begin{tabular}{|lllllllll|} 
Leptin $(\mathrm{ng} / \mathrm{mL})$ & $31.2 \pm$ & $48.1 \pm$ & $18.1 \pm$ & $51.6 \pm$ & $12.9 \pm$ & $35.4 \pm$ & $16.4 \pm$ & $38.7 \pm$ \\
& 3.0 & $2.2^{\#}$ & 2.5 & $4.8^{\#}$ & $3.1^{*}$ & $4.0^{\#}$ & 3.1 & $4.4^{\#}$ \\
\hline Fasting glucose & $133 \pm$ & $170 \pm$ & $117 \pm$ & $137 \pm$ & $119 \pm$ & $191 \pm$ & $108 \pm$ & $130 \pm$ \\
$(\mathrm{mg} / \mathrm{dL})$ & 15 & 11 & 11 & 8 & 12 & $11^{\#}$ & 10 & $6^{\beta}$ \\
\hline
\end{tabular}

Data represent mean \pm SEM for 7-11 mice per group.

${ }^{\ddagger} P<0.05$ between male and female mice fed the control diet.

${ }^{\#} P<0.05$ between mice fed control diets and high-fat diet (HFD).

${ }^{\dagger} P<0.05$ between male mice fed HFD.

$\S P<0.05$ between female mice fed HFD.

${ }^{\beta} P<0.05$ between male and female mice fed a HFD.

${ }^{1}$ For body mass composition, $n=3-4$ and were performed after 3 month of diet administration.

\section{Figures}



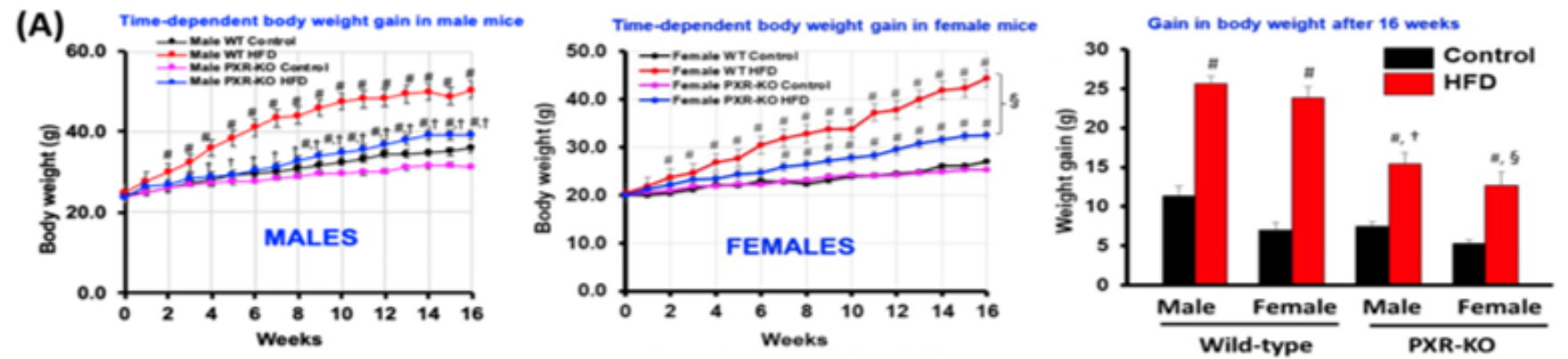

(B)
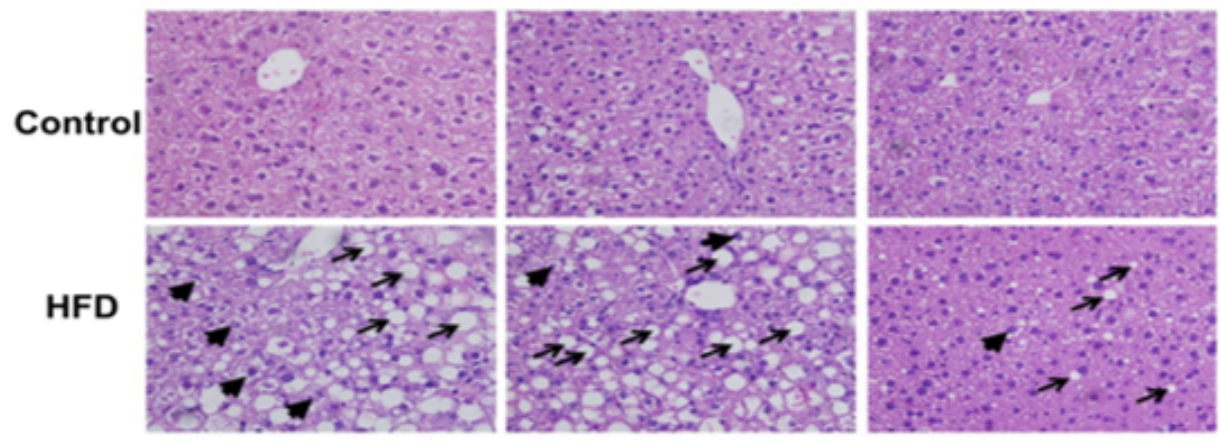

Male WT

Female WT

Male PXR-KO

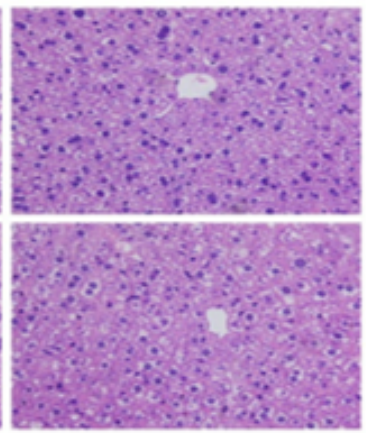

Female PXR-KO

(C)

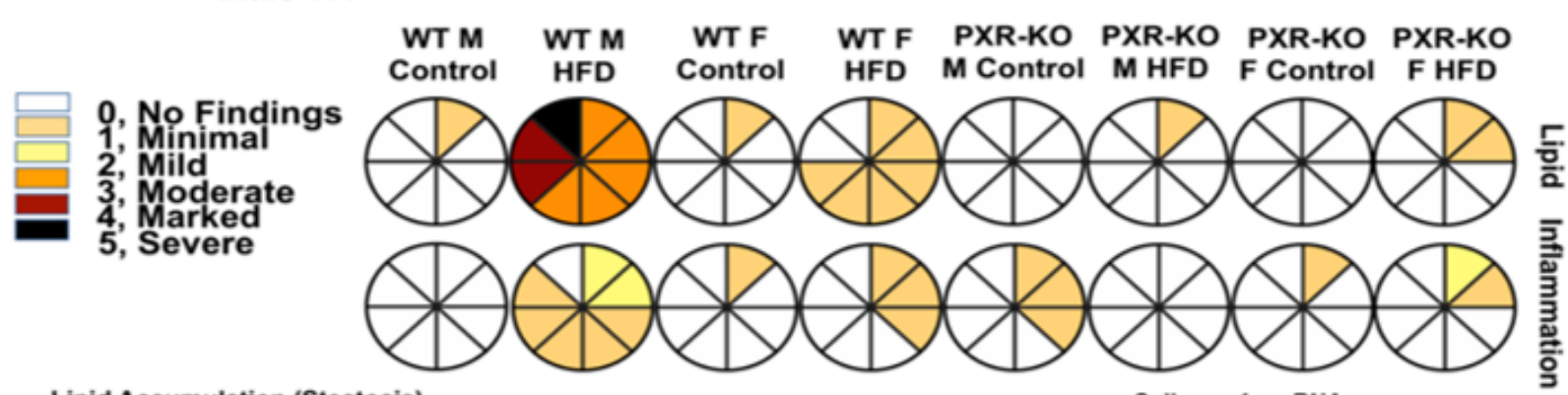

(D)

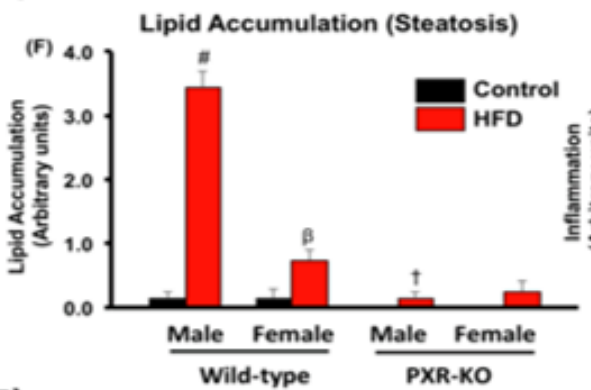

(G) Inflammation

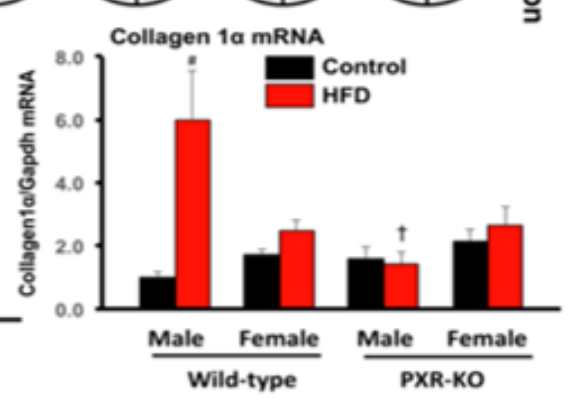

(E) IPGTT - Male WT mice

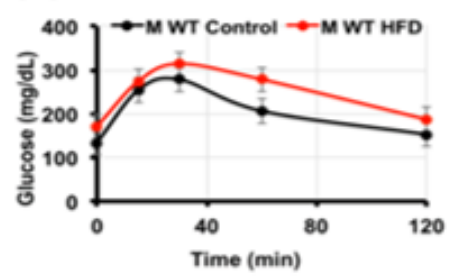

IPGTT - Female WT mice
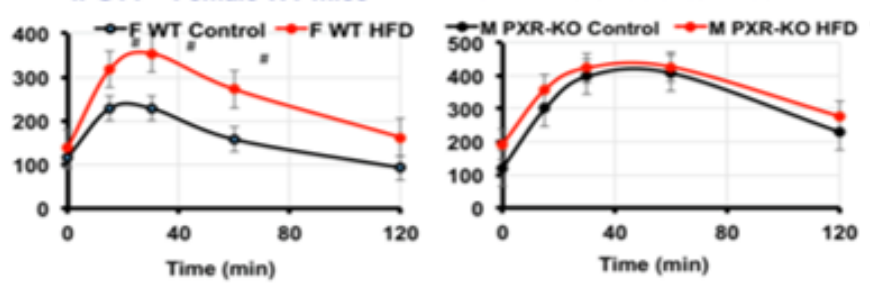

IPGTT - Male PXR-KO mice

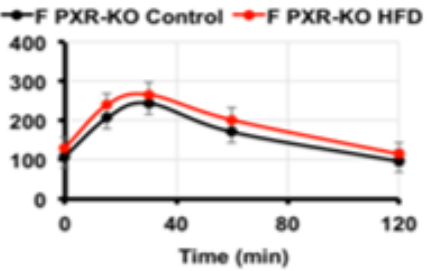

Figure 1

The effect of HFD on obesity phenotypes. (A), Body weights of mice during 16 weeks feeding of a control diet or a HFD. (B), H\&E staining of liver sections in control diet and HFD -fed WT and PXR-KO male and female mice. (C), Lipid accumulation and inflammation pathology scores from histology score of liver sections in control diet and HFD-fed WT and PXR-KO mice. (D), Liver accumulation (steatosis), inflammation, collagen 1a mRNA scores from histology of liver sections in control diet and HFD-fed WT 
and PXR-KO mice. (E), Blood glucose levels during GTTs in WT and PXR-KO mice fed control diet or HFD for 120 minutes. Data represent mean \pm SEM $(n=7-11)$. \#P $<0.05$ between mice fed control and high-fat diet (HFD). $+P<0.05$ between male mice fed HFD. §P $<0.05$ between female mice fed HFD. \#P $<0.05$ between mice fed control diets and high-fat diet (HFD).

A. M WT up-regulated by HFD

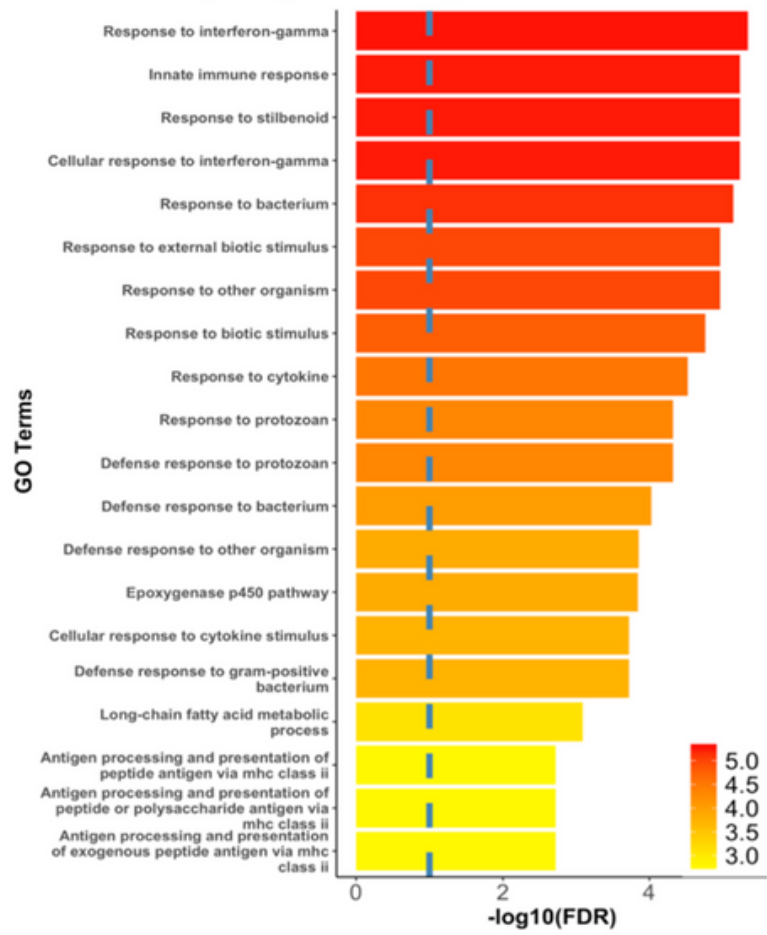

C. M WT down-regulated by HFD

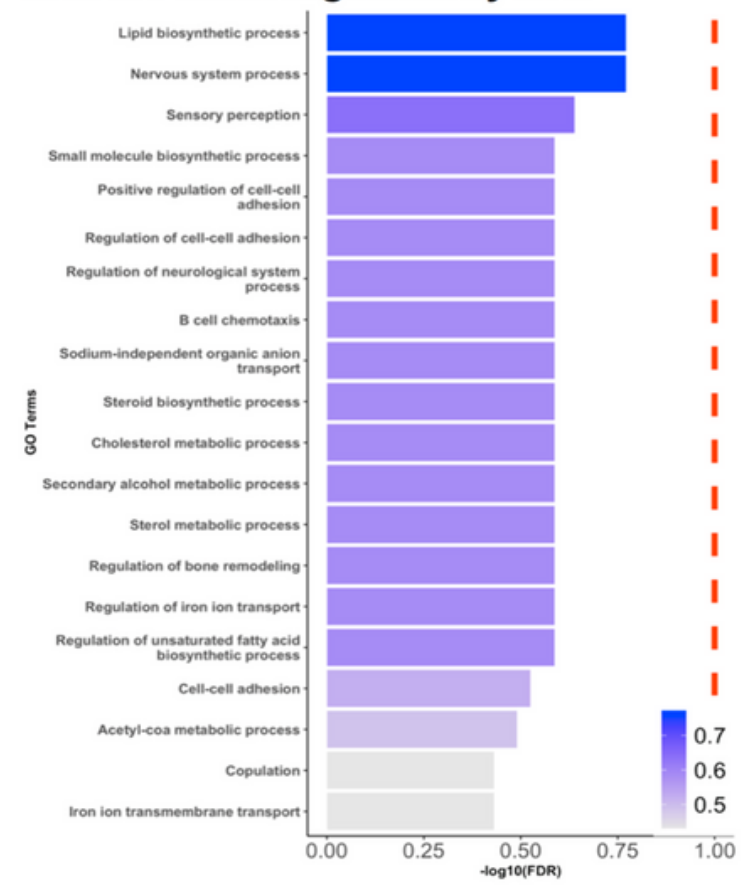

\section{B. M PXR-KO up-regulated by HFD}

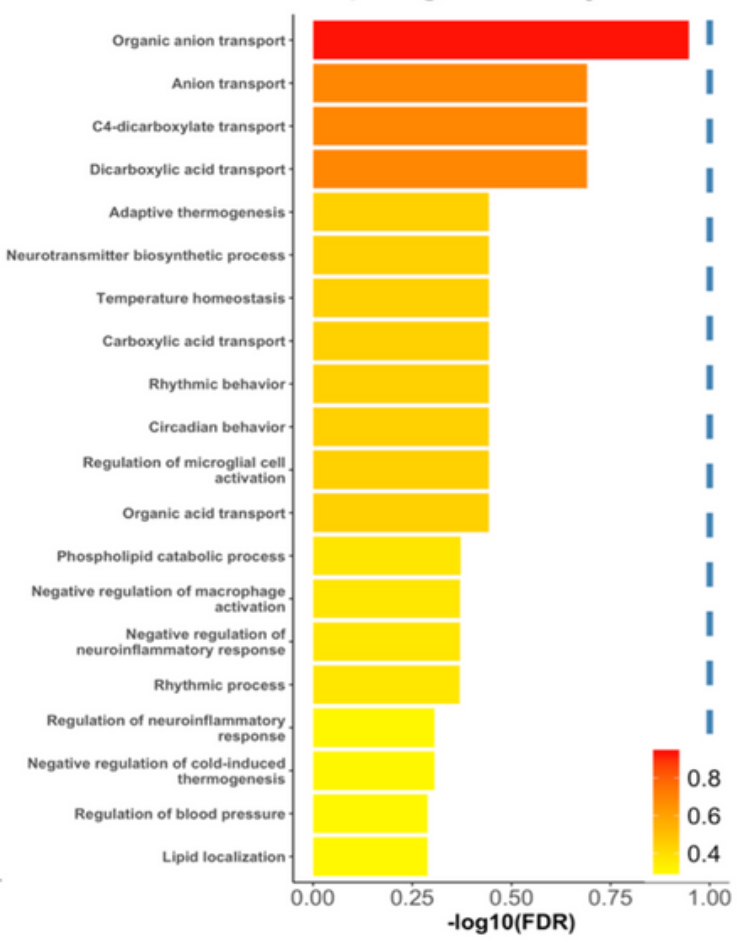

D. M PXR-KO down-regulated by HFD

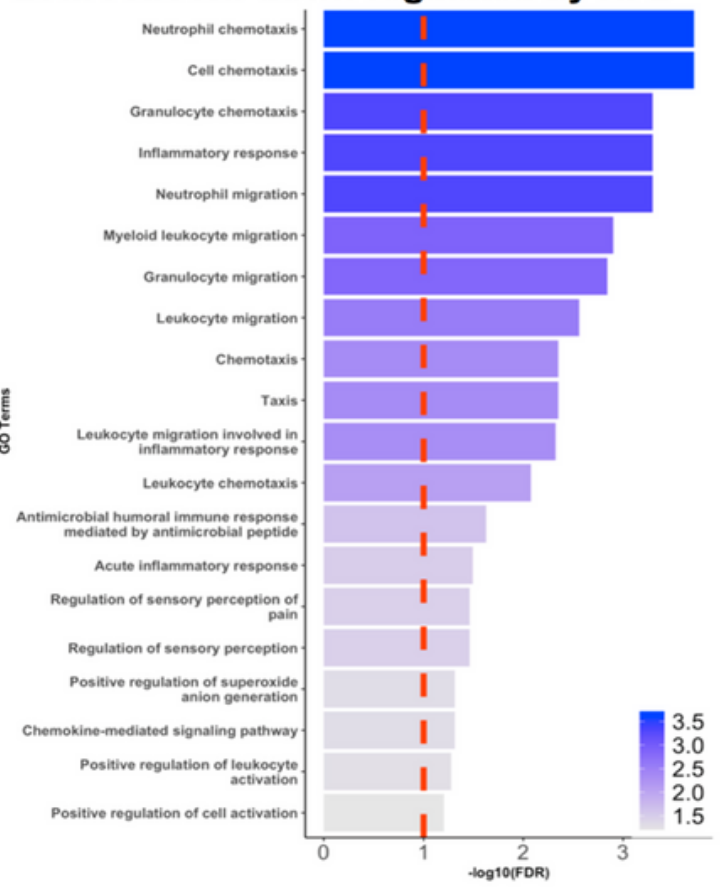

Figure 2 
The effect of HFD on gene ontology analysis. (A), Up-regulated gene ontology enrichment terms for male WT mice regulated by HFD. (B), Up-regulated gene ontology enrichment terms for male PXR-KO mice regulated by HFD. (C), Down-regulated gene ontology enrichment terms for male WT mice regulated by HFD. (D), Down-regulated gene ontology enrichment terms for male PXR-KO mice regulated by HFD. The red dotted lines represent $-\log 10(F D R)=0.1$.

(A)

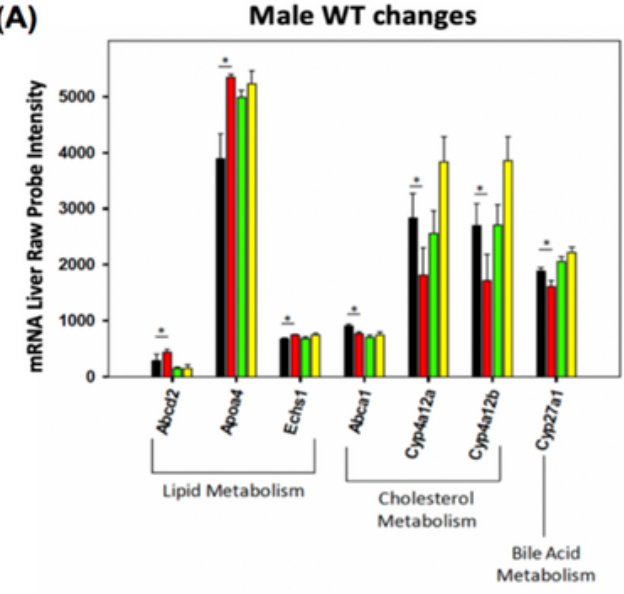

(C)

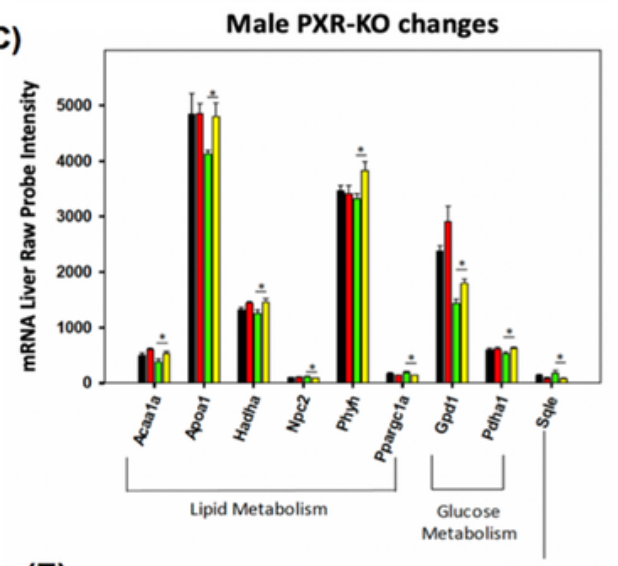

(E)

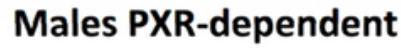

unCS_L1000_Chem_Pert_up_bar_graph

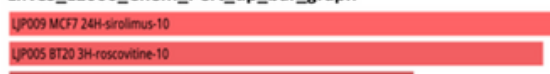

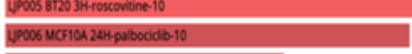

WP007 AS49 24H-dinadelib-0.37

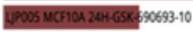

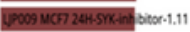

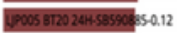

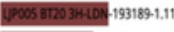

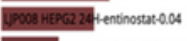

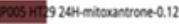

UNCS_L1000_Chem_Pert_down_bar_graph

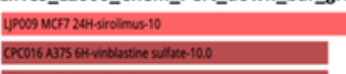

CPCOOS HT29 GH-nutin-3444

CPCOS PCO 24HChenisty 1735444

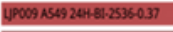

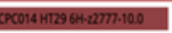

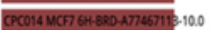

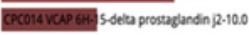

CPCO18 승 6 6Het 018159-10.0

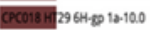

(B)

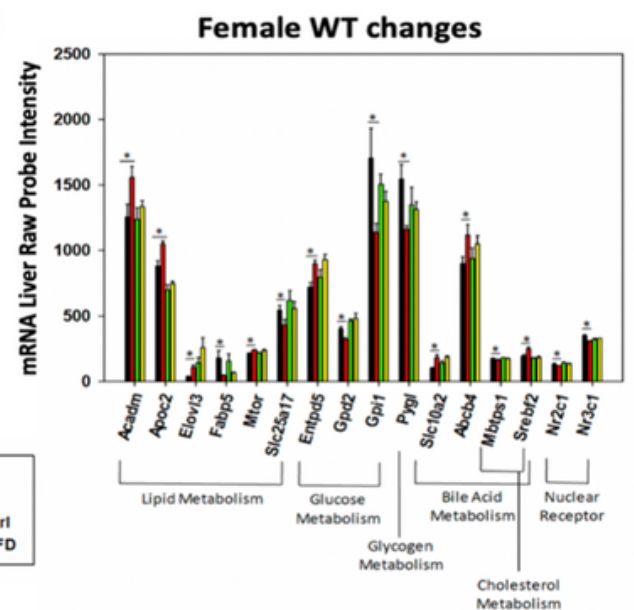

(D)

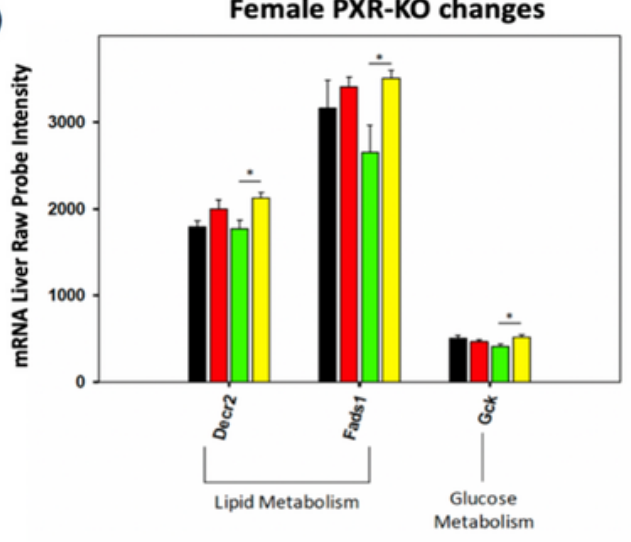

Females PXR-dependent

uNCS_L1000_Chem_Pert_up_bar_graph CPCO13 ASC 24H-BRD-A10S23515-10.0

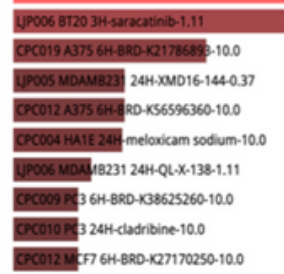

LINCS_L1000_Chem_Pert_down_bar_graph

CPCO13 ASC 24H-8RD-A10523515-10.0

UPCO5 8720 24H-6SK-690693-0.12

CPCO06 0375 6H-d1-pdmp-64.0

CPCO14 VCAP 6H-BRD-K19540840-10.0

CPC006 A375 6H-valdecorib-177.6

CPC014 PC3 24H-13644-10.0

UPOO6 HME1 24H-ZT K.474-0.12

CPCO09 V VAP $6 \mathrm{H}$-matenide hydrochloride- 10.0

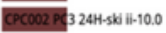

UP006 8T: 0 3H-MK-2206-0.12

Figure 3 
The effect of HFD on mRNA expressions. (A-B), mRNA expression of intermediate metabolisms separated by male and female WT changes. (C-D), mRNA expression of intermediate metabolisms separated by male and female PXR-KO changes by real time PCR analysis in liver. (E), PXR-dependent changes of HFD predicted genes and chemicals from LINCS database. Asterisks ${ }^{*}$ ) represent statistically significant differences as compared with control diet and high fat diet groups.

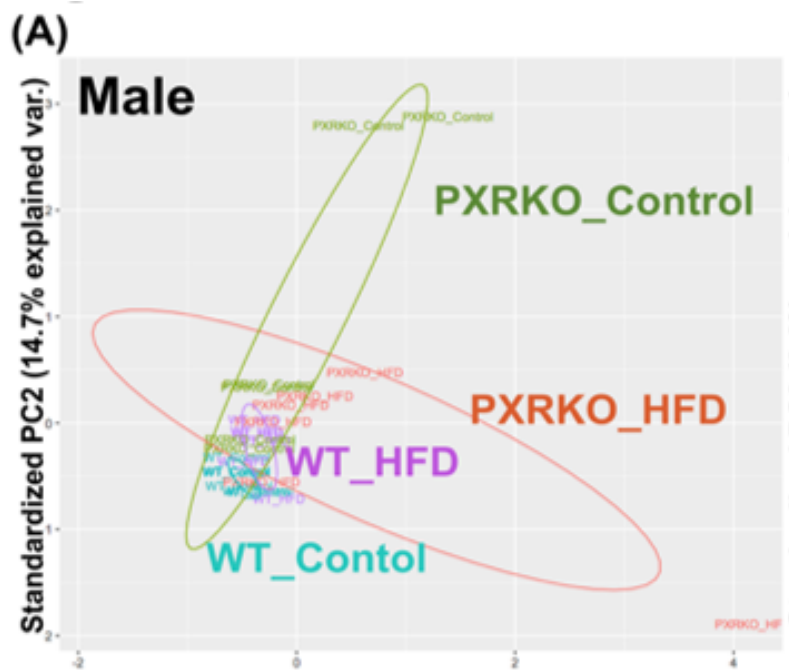

Standardized PC1 (20.4\% explained var.)

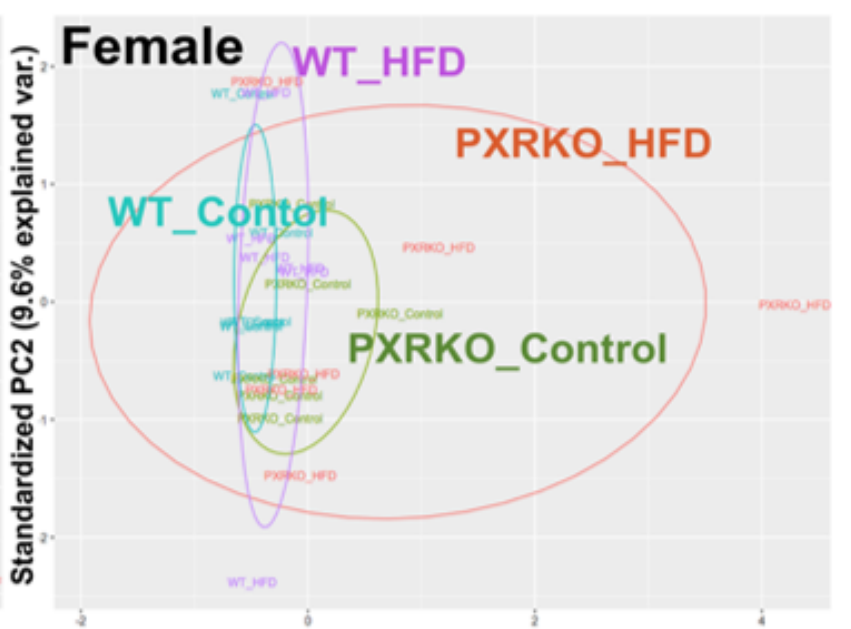

Standardized PC1 (20.1\% explained var.)

(B)
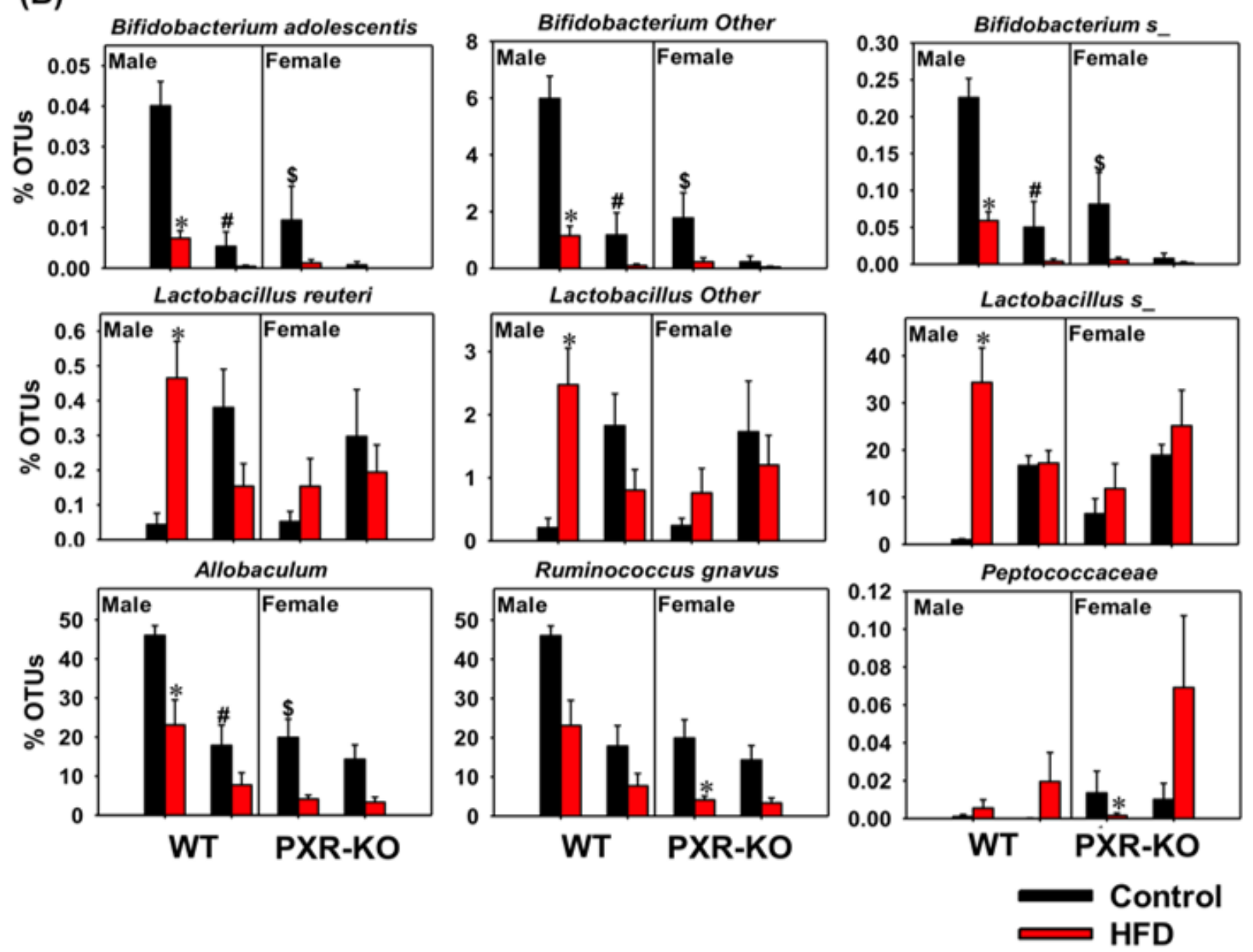

Figure 4 
The effect of HFD on the gut microbiome. (A) Beta diversity of male and female. (B) Differentially regulated bacteria in a species level. Asterisks $\left({ }^{*}\right)$ represent statistically significant differences as compared with control diet and high fat diet groups; pounds (\#) represent statistically significant differences as compared with WT and PXR-KO genotype groups (two-way ANOVA; statistical significance was considered at $p<0.05$ ).

(A)

$\square$ WT_Ctrl $\square$ WT_HFD $\square$ PXR-KO_Ctrl $\square$ PXR-KO_HFD

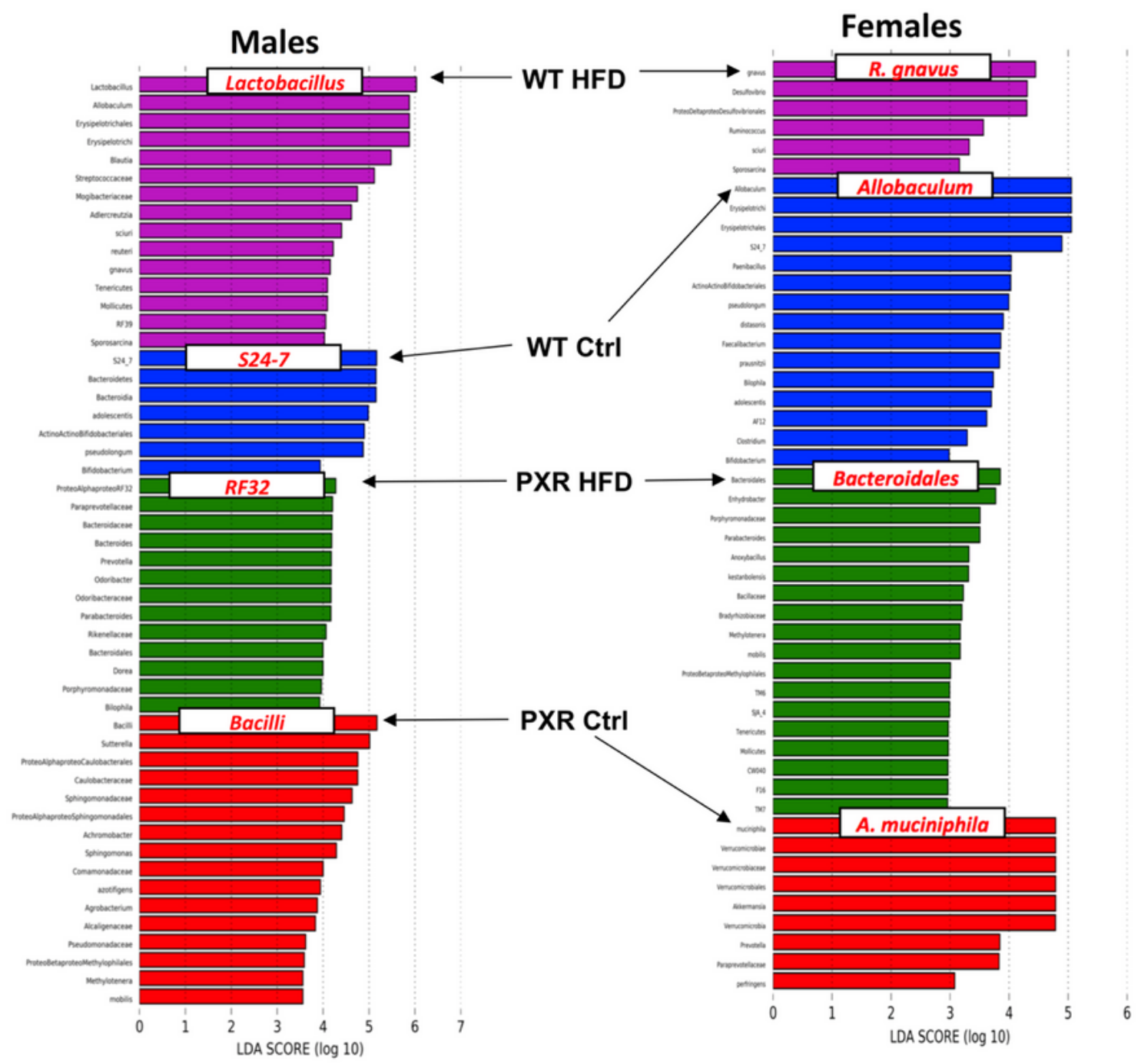

(B)

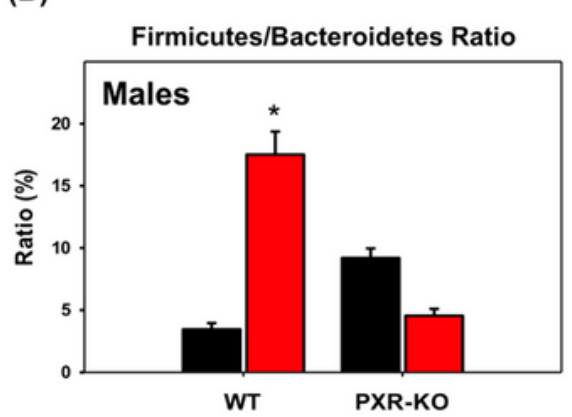

\begin{tabular}{|r|} 
Ctrl \\
HFD \\
\hline
\end{tabular}

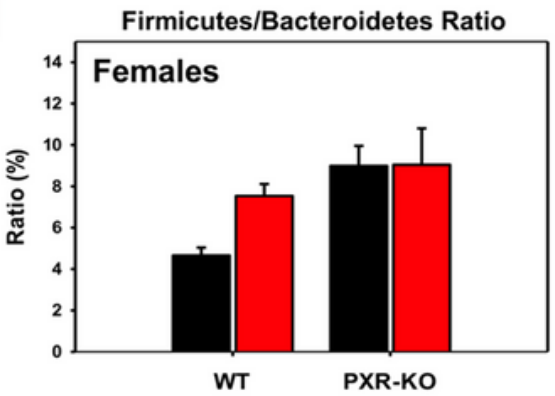

Figure 5 
The effect of HFD on bacteria species level. (A), LEfSe (Linear discriminant analysis Effect Size) of males and females WT and PXR-KO control and high fat diet fed. (B), Ratio of F/B of WT and PXR-KO control and HFD. Asterisks $\left({ }^{*}\right)$ represent statistically significant differences as compared with control diet and high fat diet groups.

(A) Males, PXR-dependent genes by HFD

$$
\begin{gathered}
\text { g_Allobaculum.s } \\
\text { g_Lactobacillus.s reuter } \\
\text { g_Lactobacillus.s } \\
\text { g_Lactobacillus.Other } \\
\text { f S24.7.g.s. } \\
\text { g_Bacteroides.s caccaē }
\end{gathered}
$$

g_Bifidobacterrium.s_pseudolongum g_Bifidobacterium.s adolescentis

g_Bifidobacterium.s

(B) Females, PXR-dependent genes by HFD
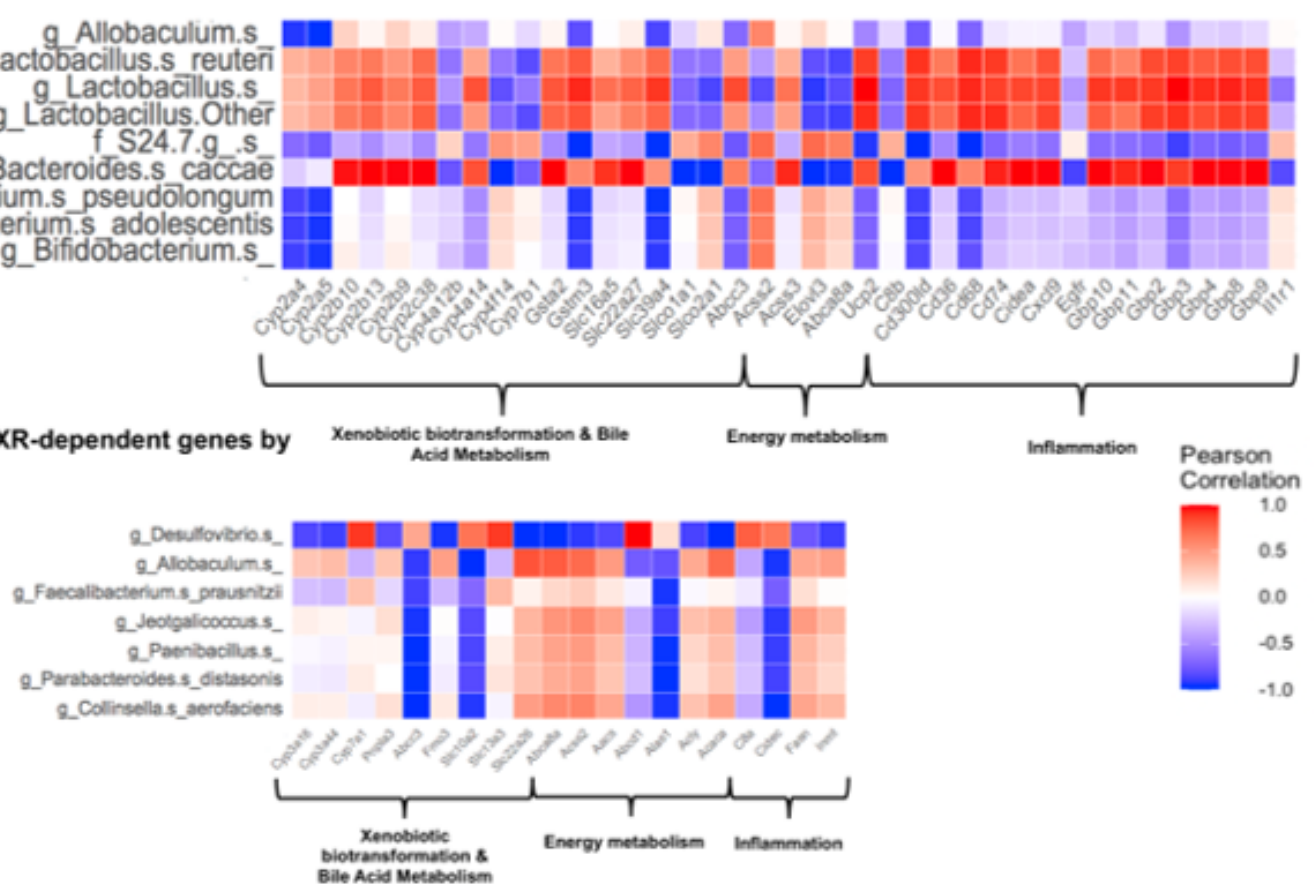

(C) Males, bacteria and liver bile acids

Pearson's Correlation g_Allobaculum.s_ g_Lactobacillus.s_reuteri g_Lactobacillus.s_ g_Lactobacillus.Other f_S24.7.g_.s_

g_Bacteroides.s_caccae g_Bifidobacterium.s_pseudolongum g_Bifidobacterium.s_adolescentis g_Bifidobacterium.s_

(D) Females, bacteria and liver bile acids

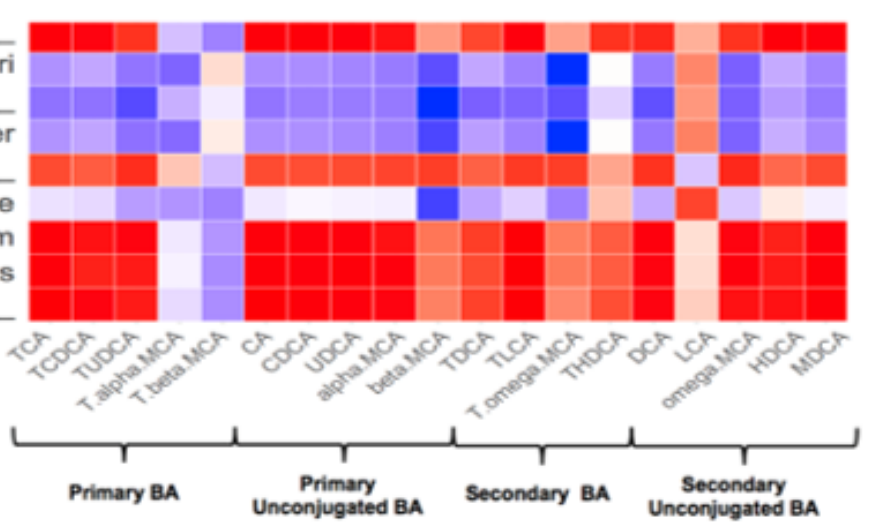
Pearson's Correlation

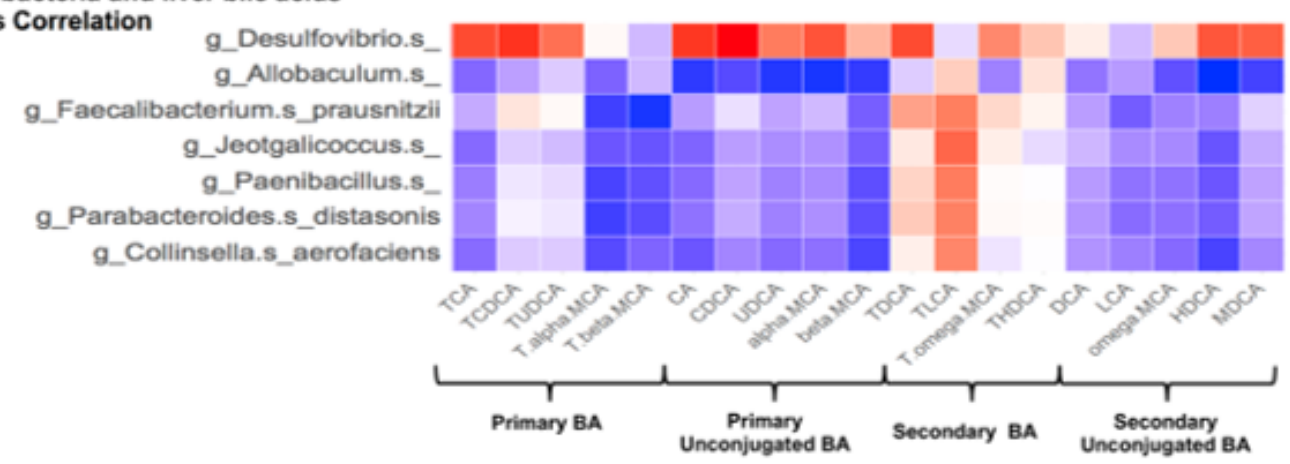

Figure 6 
Pearson correlations of male and female PXR-dependent by HFD. (A-B), Pearson correlation of males and females PXR-dependent genes by HFD with significant bacteria. (C-D), Pearson correlations of males and females liver bile acids with significant bacteria.

High fat diet-induced NASH

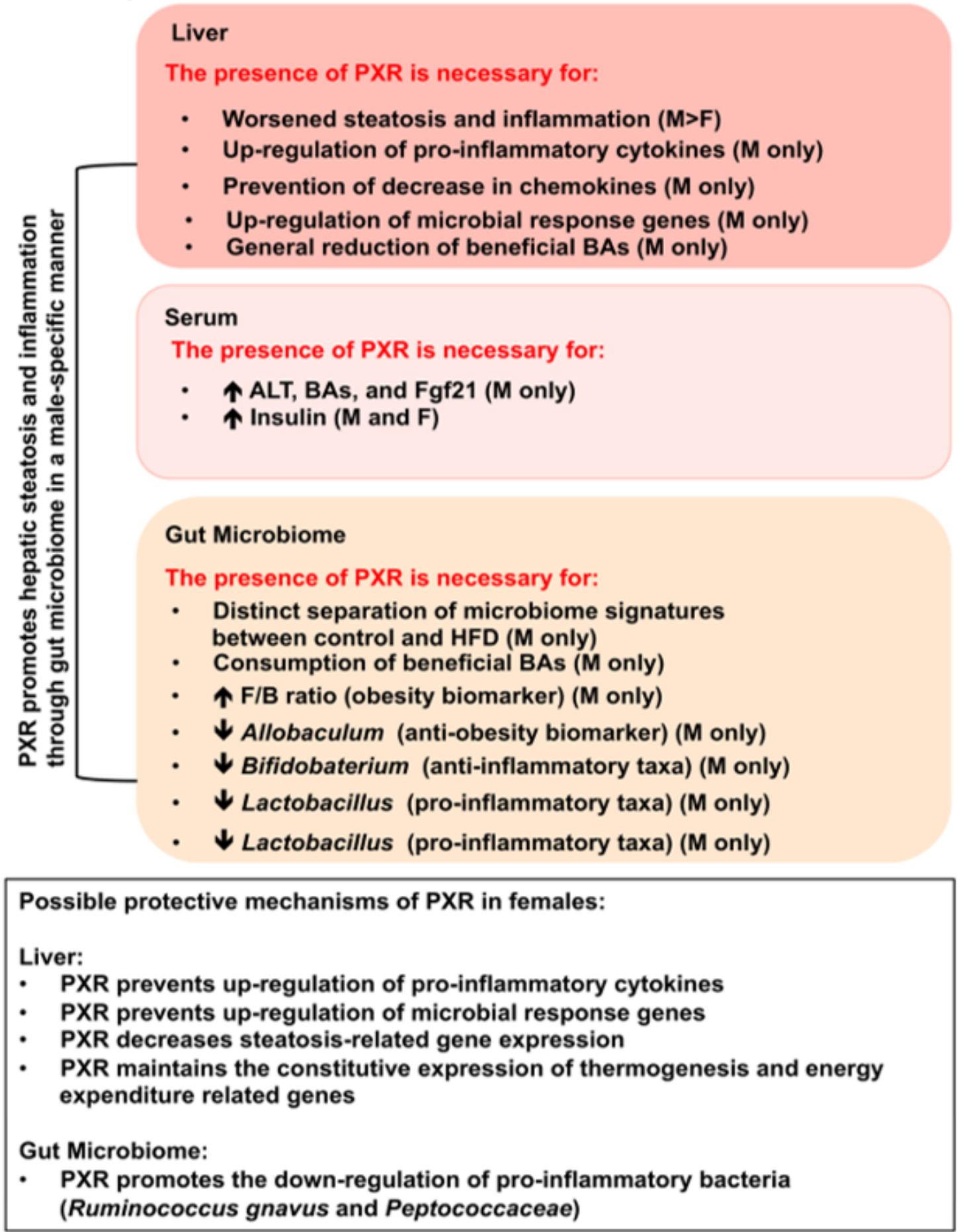

Figure 7

Summary diagram of the overall idea and outcome of the project. PXR promotes hepatic steatosis and inflammation through gut microbiome in a male-specific manner. 


\section{Supplementary Files}

This is a list of supplementary files associated with this preprint. Click to download.

- SarahsupplefiguresNC.docx

- SarahsuppletablelegendsNC.docx

- SarahTableS1S6NC.xIsx 